\title{
A New Karaite-Turkish Manuscript from Germany: New Light on Genre and Language in Karaite and Rabbanite Turkic Bible Translations in the Crimea, Constantinople and Elsewhere
}

\section{Dan Shapira}

Bar-Ilan University

\begin{abstract}
A Karaite manuscript in Istanbuli Turkish written in Hebrew characters has turned up in Germany lately. This article investigates the whereabouts of the manuscript and tries to place it in its historical and linguistic context. Although the manuscript was apparently written/copied in Constantinople, the Turkic language used in it has some Crimean connections. The novelty of this discovery lies in the fact that Turkish was used by the $19^{\text {th }}$ century Constantinople Karaites as a literary language.
\end{abstract}

\section{Keywords}

Karaite Turkic, Judeo-Turkic, Turkish, Karaim, Karaite, Qrimchaq/Krymchak, Jewish Bible translations, Crimea, Constantinople/Istanbul, manuscripts

In the Spring of 2013, a collector from Germany established contact with me asking some questions about several manuscripts written in Hebrew letters in his possession. The collector wished them to remain anonymous for the time being. It appeared that two of his manuscripts were copied by Karaites in the Romaniot-Byzantine script used by the Karaites of Constantinople, from which the script of the Crimean and Eastern-European Karaites is derived as well. One of these two manuscripts is a copy of an obscure Hebrew work by a late $19^{\text {th }}$ century German Orthodox rabbi, known only to the best specialists in the late-19 $9^{\text {th }}$-century Jewish-German life and history; why a Constantinople Karaite would make a hand-written copy of a late and 
obscure German-Rabbanite work remains a mystery to me, but we do know that the copying choices of the Karaites were sometimes rather unexpected.

The owner of the manuscripts seems to cherish this work especially, because he is interested in Judaica-Germanica, and this hand-written Karaite copy of such a late Jewish-German work is, indeed, a rarity, if not a unica.

However, to me, it is the other manuscript that seams to be of greater value. It was written, I assume, in the latter half of the $19^{\text {th }}$ century and contains Turkic translations of a number of shorter Biblical books and some grammatical material on Hebrew. The language of the Biblical translations is Constantinople-Turkish Umgangssprache, thus the importance of the manuscript. As far as I know, this is the first known Constantinople-Turkish Bible translation made by Karaites, besides the idiosyncratic Ottoman-Turkish-cumLutsk-Karaim translation prepared by Avraham Firkowicz in the early 1830 s in Constantinople. ${ }^{1}$

There is an insistence on the predominantly Greek-speaking character of the Karaite community of Constantinople. ${ }^{2}$ However, many of Constantinople's Karaites were Crimeans by origin or the children of Crimeans; the Hasköy Karaite cemetery of Constantinople is full of people whose Crimean provenance is obvious. Avraham Firkowicz tried to create a pan-Karaite Turkic written language precisely because the Karaite community of Constantinople was of mixed character, including locals and Crimeans.

I am not trying to claim that Constantinople's Karaites (or, the majority of them) did not speak Greek as their first language; I am claiming that the question of Greek is irrelevant when we encounter texts in Turkish composed by Constantinople Karaites for inner-community purposes. It has frequently been found, especially in the last few centuries, that Jews used for their inner-Jewish purposes the languages of their countries (or international languages such as German or French), which were not their mother tongues. ${ }^{3}$

${ }^{1}$ See Shapira 2003a; SHAPIRA 2003b: 1-19.

2 Harviainen 1998: 349-356.

3 For example, English has become the inner-Jewish lingua franca in the Scandinavian and German-speaking countries in the last twenty or so years. Jews in the $19^{\text {th }}$ and $20^{\text {th }}$ centuries in Eastern Europe, though speaking Yiddish and sometimes Hebrew, were producing, at the same time, texts in other languages, for use inside the same language community to which they themselves belonged. In the case of the Ottoman Jewry in the late $19^{\text {th }}$ century, French became such a language. 


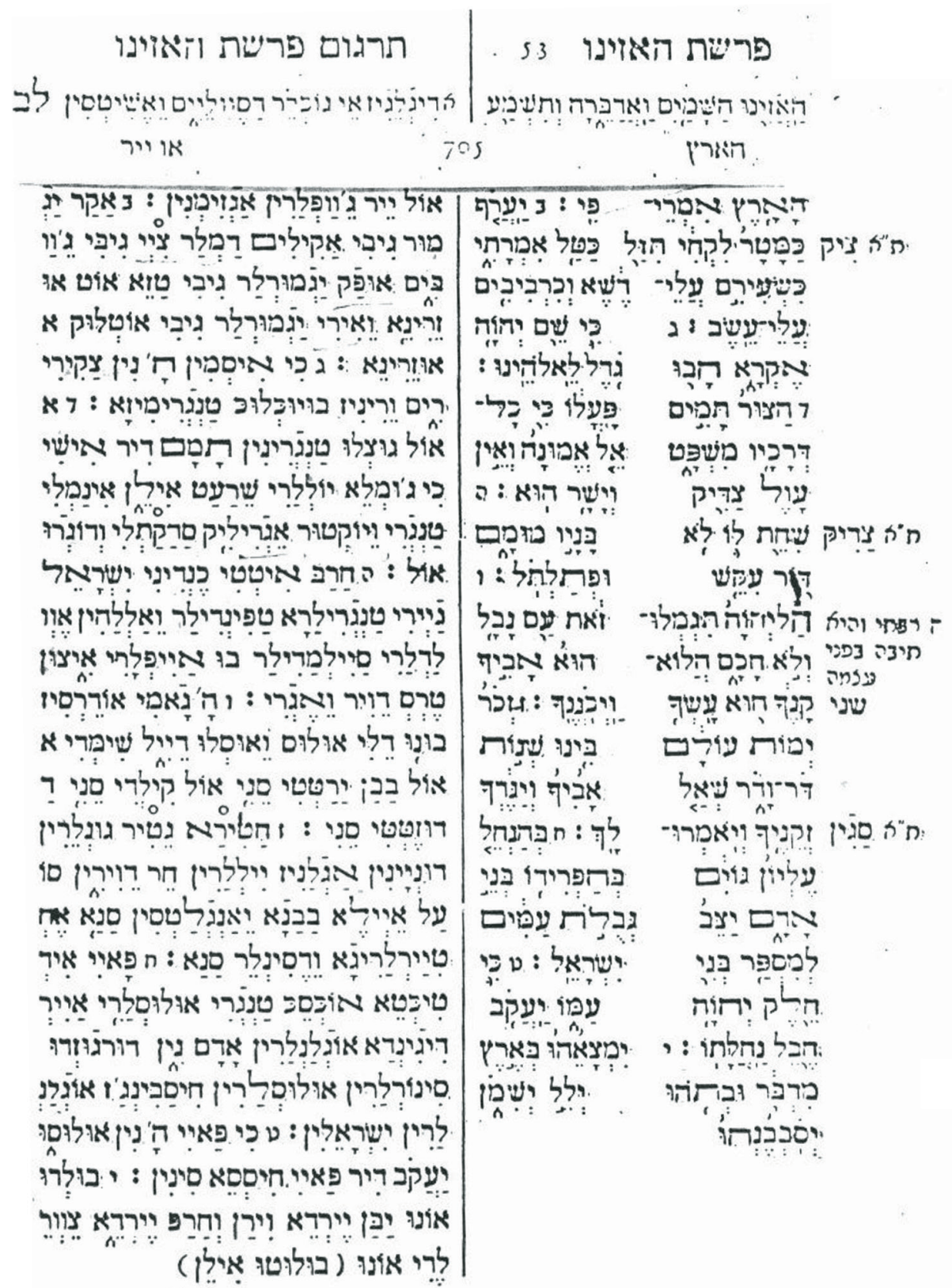

A fragment from Avraham Firkowicz's Turkic Bible (Pentateuch) translation, Constantinople 1833. 
This is also the case of this Judeo-Turkish Karaite MS from Germany, as I shall demonstrate.

The collector in Germany knew nothing about when and how he had come into possession of these manuscripts; first, he believed his father had somehow obtained them. Then, the collector found in his notebooks that he had acquired the manuscripts together with other unchecked old Jewish books in a New York antiquities shop earlier that year. The name of the collector is Rabbi Moshe Baumel of Osnabrück. As I said, the collector is interested in Judaica-Germanica and, before he contacted me, the collector was unaware of the nature of these two manuscripts that turned out to be Karaite. It appears that R. Baumel had just stumbled onto a treasure in a New York antiquities shop and, apparently, the seller was not aware of what he was selling as well. This much is known so far about the provenance of this manuscript, but later I would suggest that at least one of the manuscripts (and, possibly, both) was bought in Constantinople by Elkan Nathan Adler (1861-1946).

The name Yepheth, Japheth, is attested among the members of two Jewish sub-ethnic groupings only - the Karaites and the Yemenis. Japhet is a wellknown Karaite personal and family name in Constantinople, in the Crimea and in Egypt; it is unattested among the Karaites of Troki, Halicz or Łuck. On one of the first pages of the manuscripts are mentioned Moshe Yepheth, Eliya Yeraqa, Avraham Yepheth, and Avraham ben Yișhaq Yepheth. The two last persons might, of course, be the same. Yeraqa was a Karaite family in Constantinople with connections to the Crimea, for example, the brothers Afedah and Shabbetai Yeraqa from Constantinople set up a Hebrew press at Çufut-Qal'eh in 1734.

The computerized version of Samuel Poznanski's Hebrew Encyclopaedia of Karaites has no entries on Moshe Yepheth, Eliya Yeraqa, Avraham Yepheth, but it does have an entry on one Yișhaq Yepheth, who was a hazzan and a melammed in Constantinople in 1836/7 and father-in-law of Yișhaq ben Moshe Qirimi Qusdini, a leader of the Karaites of Constantinople who played a role in the Karaite protest brought before the hakham-başı Rabbi Yaqir Presiado Astruc Gueron (1813-1874)4 against Shelomo ben Nissim

4 This rather liberal Chief Rabbi of Adrianople was promoted to the office of the Chief Rabbi of Constantinople and the Ottoman Empire by Sultan Abdülaziz (r. 1861-1876) in 1863 and held this office till 1871/2, when he left for Jerusalem. 


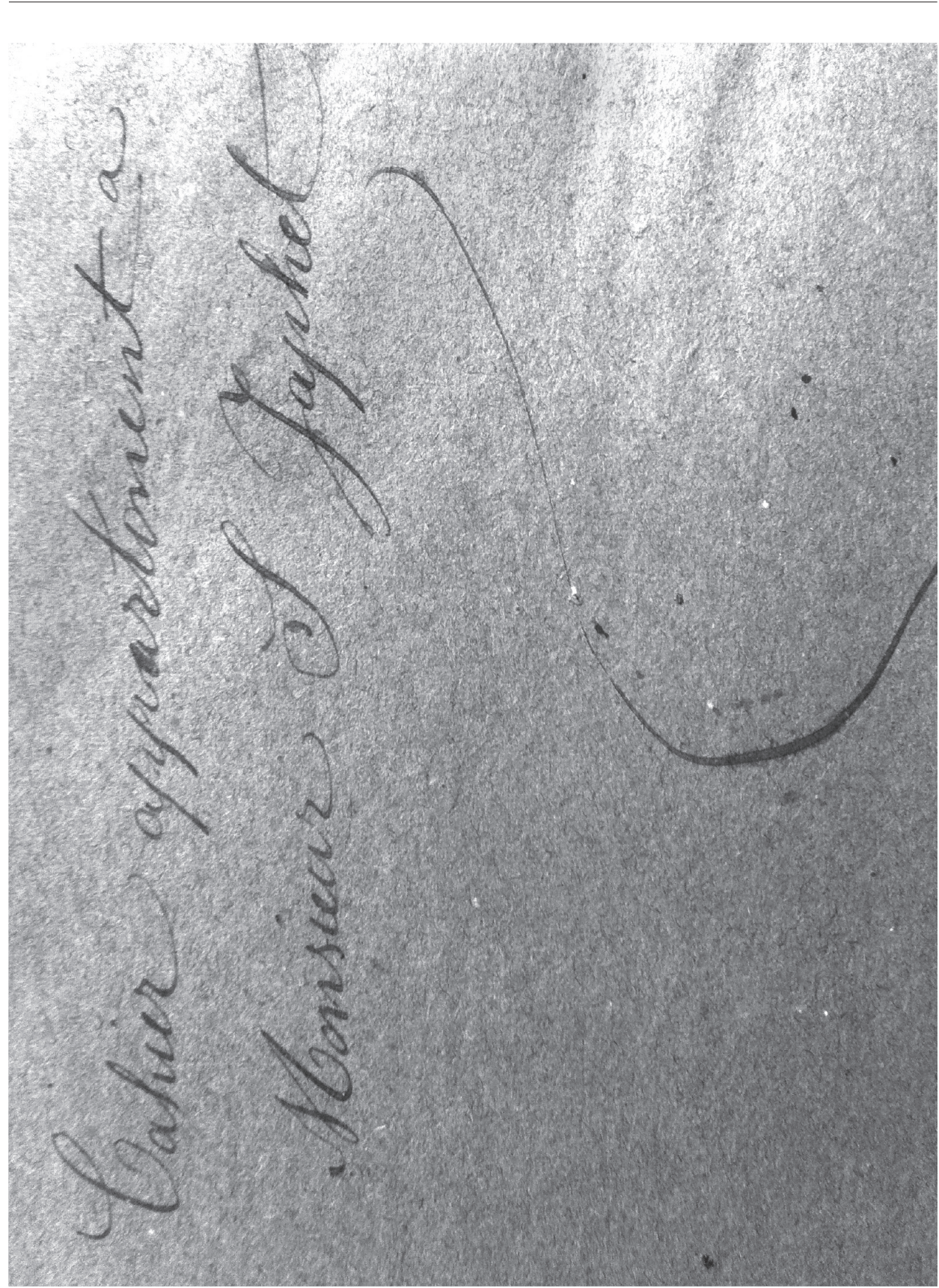

On the manuscript there is written in French: notebook belonging to Mr. I. Japhet. 
Qimhi and his anti-Karaite book in the late $1866^{5}$ (en passant, the very name "Qirimi Qusdini”, meaning “Crimean-Constantinoplean”, hints to the mixed origins of the leader of this Karaite community). Adler bought from the widow of Yișhaq ben Moshe Qirimi Qusdini, the daughter of Yișhaq Yepheth, many manuscripts, ${ }^{6}$ and it is not impossible that the manuscript under scrutiny was among them.

Yișhaq Yepheth, whom Yișhaq ben Moshe Qirimi Qusdini has mentioned as his father-in-law and his teacher, ${ }^{7}$ was possibly the grandson of another Yișhaq (ben Eliyau) Yepheth, one of the richest Karaites of Constantinople in the late $18^{\text {th }}$ century, who went heavily into debt in order to support the Karaite community of Jerusalem. ${ }^{8}$

\section{The contents of the manuscript}

The contents of the manuscript are: a list of the parashoth: Yithro Friday, Mishpatim Monday, Terumah Monday, Teșawweh Monday, Ki Tiśśa' Monday, WaYiqra' Monday; ${ }^{9}$ then there are three cut-out pages, a translation of Proverbs, 20 plus fol; Song of Songs, four plus fol.; Jonah, two fol.; Esther, 8,5 fol.; Ezra, 5,5 fol. ending in the middle of chapter 7, then two opposing pages of Hebrew grammar, then 4,5 fol. of Ezra till the end; Ruth, 3,5 fol.; Lamentations, 4,5 fol.; Habbakuk, two fol.; Malachi, 2,5 fol.; Obadiah, two opposing pages; Daniel, 17,5 fol.; then about a dozen blank pages.

Here I provide the text of the translation of Obadiah from the manuscript. I chose this particular Biblical book because it is the shortest in the whole of the Bible, consisting of one chapter only. The Latinized transliterated text is given in the second column from the left; the Hebrew original on the right, the fourth column from the left; the first left column is a Modern Turkish version

\footnotetext{
5 The anti-Karaite and anti-modernist book Melekheth Shelomoh was published some four years earlier (1862) in Salonica. The author was a conservative and a follower of R. Yișhaq ben Avraham Aqrish, the leader of the anti-modernist Jewish-Ottoman fraction. The book sparked fierce protests by the Karaites, and R. Gueron ordered it to be burned.

${ }^{6}$ ADLER 1905: 21.

7 Yiṣhaq Yepheth was mentioned by Yiṣhaq ben Moshe Qirimi Qusdini as deceased in 1884/5.

8 Mann 1935, II: 327, 380, 400.

9 These seem to be notes for a cantor (implying that in the community there are at least two cantors; we know that in the early 1830 s, the Constantinople Karaites used to divide the Torah readings between two cantors), or for a melammed.
} 
taken from a Missionary edition. I am including the Modern Turkish texts for the convenience of those acquainted with Turkic languages; in addition, it appears that the Turkish-Karaite translation of Obadiah has two points of similarity with the Missionary translation on understanding some particular points of the Hebrew original.

The third column from the left is a latinized version of Obadiah taken from the Gözleve Bible printed in 1841. The reader shall see that the author of the Constantinople-Turkish translation from the Osnabrück MS was cognoscente of the Gözleve Bible, used the same priciples of rendering Hebrew grammatical elements into Turkic, and sometimes used the same fixed Karaim equivalents for Hebrew words.

The system of transliteration I use here for the Judeo-Turkic texts is based on a mechanically Latinized reproduction of the Hebrew characters and symbols; I do not use symbols lacking in Hebrew, such as $\ddot{u}$ and $\ddot{o}$, for there is no possibility to represent them by using Hebrew script (exactly as in OttomanTurkish). I am aware of the shortcomings of this system, but it has the advantages of reflecting the way the authors of the texts grasped their language. For a Turcoligst, this system is not more complicating than reading, say, a fullyvocalized text in Ottoman-Arabic or in Karaim-Hebrew characters.

Examples of the Turkish as used by Constantinople's Greeks and Armenians 100-150 years ago show that the rules of vowel harmony were very lax. We cannot know, but we might suggest that those Karaites for whom Turkish was not their first mother tongue but rather the second one or third, the situation was similar to that of the Turkish-speaking Greeks and Armenians. In any case, it is of no importance to me if the author of the Osnabrück MS pronounced 'WPTY or 'WPTY as opty, opti, or öptü. Personally, I am certain the author pronounced it as öptü. They are all dead now and we cannot ask them. What IS important, in my opinion, is HOW the author wrote his speech and WHY he did so this way. We can tell a lot from the author's spellings. If the author of the Osnabrück MS wrote $k w c w q$ (as he did), this implies that in this dialect or in this variety of this dialect there was no distinction between $k$ and $q$. It also implies that the author's literacy in Ottoman-Turkish in Arabic letters was limited or non-existent. If the author frequently confused $n$ and $g$ while writing in Turkic in Hebrew letters, it implies either that $\eta$ was still a very prominent sound, or that $\eta$ was withering out, and the author was hyper-correcting. However, Firkowicz in the early 1830 s was still writing soyra consistently. 


\section{Obadiah}

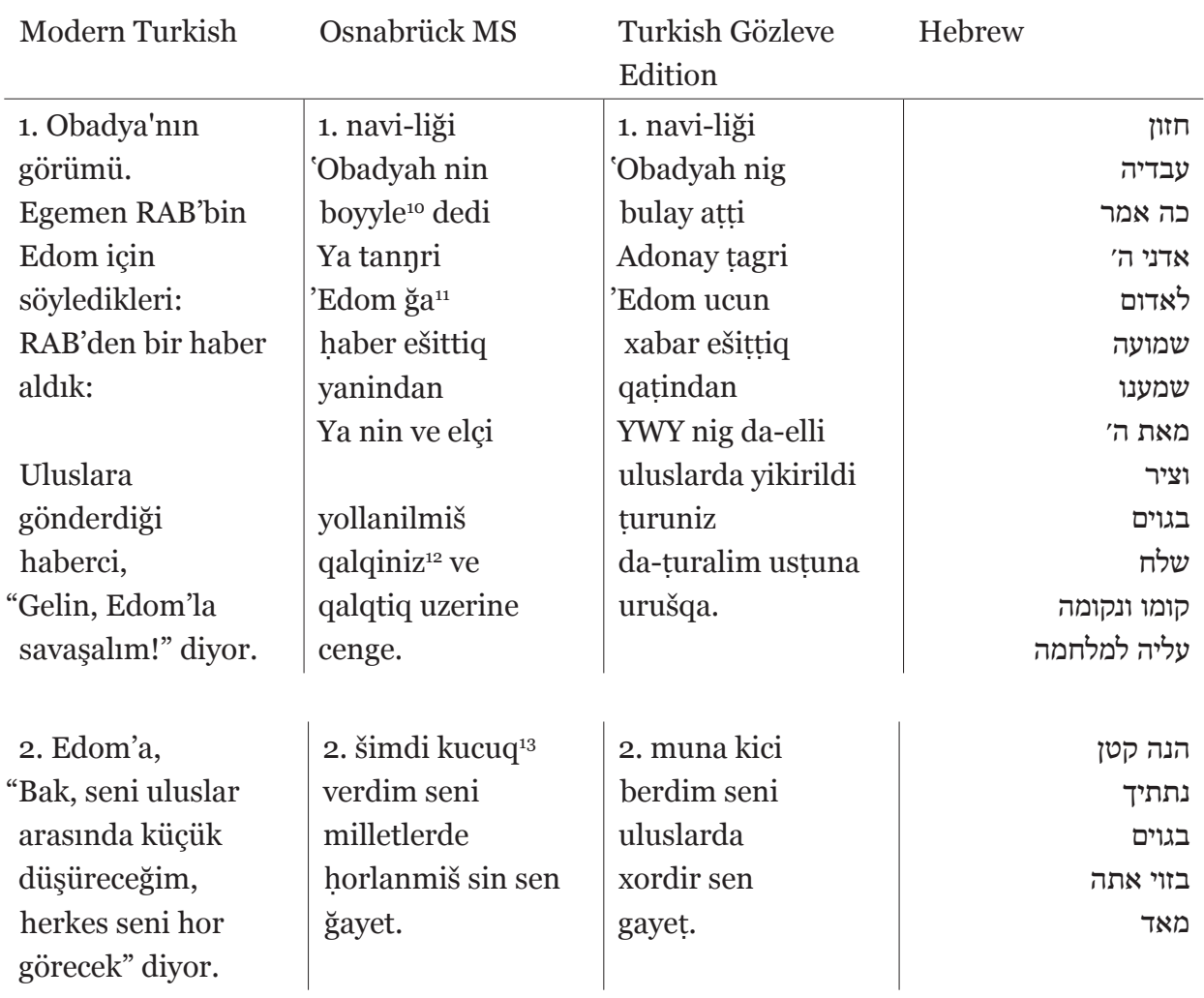

${ }_{10}$ Two Yods after a vowel and before the Y-consonant here and in other cases indicate the front pronunciation of the previous vowel.

${ }^{11}$ Note the Qipčaq-like Dative suffix.

12 A word, apparently *halqlarda, "in the nations", was omitted because of graphic similarity, before qalqiniz. This implies that the text is a copy.

${ }_{13}$ The initial Kaph indicated the front pronunciation of the vowels. 


\begin{tabular}{|c|c|c|c|}
\hline $\begin{array}{l}\text { 3. Kaya } \\
\text { kovuklarında } \\
\text { yaşayan, Evini } \\
\text { yükseklerde kuran } \\
\text { sen! Yüreğindeki } \\
\text { gurur seni aldattı. } \\
\text { İçinden, } \\
\text { 'Beni kim } \\
\text { yere indirebilir?' } \\
\text { diyorsun. }\end{array}$ & $\begin{array}{l}\text { 3. yaramaliği } \\
\text { qalbinin } \\
\text { aldati }^{14} \text { seni } \\
\text { meskan eyyle } \\
\text { quvuš larinda } \\
\text { qaya nin } \\
\text { oțurušunda } \\
\text { oqseq }^{15} \text { yerinin ki } \\
\text { dersin qalbinda } \\
\text { kim indirir } \\
\text { beni yere. }\end{array}$ & $\begin{array}{l}\text { 3. cayaliği } \\
\text { koglignig } \\
\text { aldadi seni } \\
\text { țoxțavci } \\
\text { quvušinda } \\
\text { qayanig } \\
\text { biyik yerin } \\
\text { oṭirašinig } \\
\text { ayțuvci oglinda } \\
\text { kim endirir } \\
\text { meni yerga. }\end{array}$ & שבד \\
\hline $\begin{array}{l}\text { 4. Kartal gibi } \\
\text { yükselsen de, } \\
\text { Yuvanı yıldızlar } \\
\text { arasında kursan da, } \\
\text { Oradan } \\
\text { indireceğim seni” } \\
\text { diyor RAB. }\end{array}$ & $\begin{array}{l}\text { 4. eyyer } \\
\text { oqseqlensen } \\
\text { qara quš gibi } \\
\text { veeyyer } \\
\text { qosan }^{16} \text { yyuvani } \\
\text { arasina }^{17} \\
\text { yildizlarin } \\
\text { ondan indiririm } \\
\text { seni sozu } \\
\text { Ya nin. }\end{array}$ & $\begin{array}{l}\text { 4. agar } \\
\text { biyik ețsag } \\
\text { qaraquš gibi } \\
\text { oțirašigni } \\
\text { de-egir arasina } \\
\text { yulduzlarnig } \\
\text { qoysag uyagni } \\
\text { andan endirimin } \\
\text { seni sozi } \\
\text { YWY nig. }\end{array}$ & אני \\
\hline
\end{tabular}

${ }^{14}$ It is interesting that the Gözleve Translation and the Turkish-Karaite and the TurkishChristian translations read here hiśśs' [ekha], "it/he took [you up]", and not hiššì'[ekha], "it/he provoked [you]". The missionary Turkish Bible has been updated many times and some older layers of it go back to Karaite Turkic translations, as is well known. Here we have one of these examples. On the other hand, there can be little doubt that Constantinople Karaites were sometimes consulting the missionary translation of the TaNaKh as well as the Gözleve Translation.

15 The front pronunciation is not expressed.

${ }_{16}$ Correctly grasping that Hebrew śim is a Stative.

${ }_{17}$ arasinna < arasinda? Or, a misspelling? But compare the Gözleve Translation. 


5. Hırsızlar ya da
haydutlar gece sana
gelselerdi, Yalnızca
gereksindiklerini
çalmazlar mıydı?
Üzüm toplayanlar
bağına girseydi,
Birkaç salkım
bırakmazlar mıydı?
Ama seni ne
felaketler bekliyor;

şeyi
yağmalanacak,
gizli hazineleri
ortaya
çıarılacak.

5.eyyer xirsizlar gelse ediler

sana ya

yağmağilari

gece nin

nasli sin

kesilmišs $^{18}$

çalmasa ediler

yiytišir qarar

ya oraqçilar gelse

ediler sana

buraqmaz ediler

fena ediniler.

6. nasli tebdil
oldular išleri
Esav nin
beqçileri arandilar.

5.egar ugdilar ${ }^{19}$

keldilare ediler

esa saga egar

țalovcilari

kecenig

necik kesildig

muna ugurlar

ediler

yețkililarinda egar

borla coplavcilar

keldilar esa saga

muna qaldidir

ediler cerțimlar.

6. necik țințildilar

komulmišlari

'Esav nig

izlandilar

saqlanmišlari.

7. ol sinor edeq

yolladilar seni

cumle kišeleri

šertinin aldatilar

seni qadir oldular

sana kišileri

selametinin

yiyenleri

eqmeinin

qordular yara

altina

yoqtur annamaq

ona.

\begin{tabular}{|l|} 
7. ol sinorga degin \\
uzatțilar seni \\
jumla kišeleri \\
šarțignig aldadilar \\
seni bulay aldilar \\
sana bariš \\
kišilarig \\
ileri selametinin \\
ešakcilar ašigni \\
qoydilar yara \\
yaširținlik bilan \\
yoqțur aqil anda.
\end{tabular}

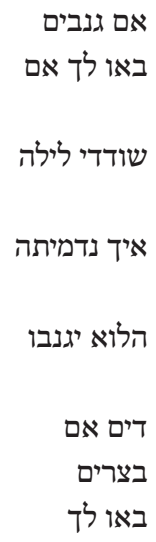

הלוא ישאירו עללות

איך נחפשו

עשוך

נבעו מצפניו

עד הגבול

שלחוך כל ענבול

אנשי שלחוך

בריתך

השיאוך

יכלו לך

אנשי שלמך

לחמך

ישימו מזור

תחתיך אין תבונה בו ישור

${ }^{18}$ For the meaning of the Hebrew word, cf. Zephaniah 1:11.

19 This is a misprint for *ugrilar, see APPENDIX I. 


\begin{tabular}{|c|c|c|c|}
\hline $\begin{array}{l}\text { 8. RAB diyor ki, } \\
\text { “O gün Edom'un } \\
\text { bilge adamlarını, } \\
\text { Esav'ın } \\
\text { dağlarındaki } \\
\text { ilgiçleri yok } \\
\text { edeceğim. }\end{array}$ & $\begin{array}{l}\text { 8. o gunde sozu } \\
\text { Ya nin } \\
\text { ve qayyib itmeim } \\
\text { kāmiller } \\
\text { 'Edom dan } \\
\text { ve aynamaq } \\
\text { dağindan 'Esav nin. }\end{array}$ & $\begin{array}{l}\text { 8. muna ol kunda } \\
\text { sozi } \\
\text { YWY nig } \\
\text { da-țas ețirmin } \\
\text { uklilarni } \\
\text { 'Edom dan } \\
\text { da-aqilligi } \\
\text { țağindan 'Esav nig. }\end{array}$ & ההוא נאם ה' והיום \\
\hline $\begin{array}{l}\text { 9. Ey Teman, } \\
\text { yiğitlerin öyle } \\
\text { bir korkuya } \\
\text { kapılacak ki, } \\
\text { Esav'ın } \\
\text { dağlarında } \\
\text { bulunanların } \\
\text { hepsi } \\
\text { Kıyıma uğrayıp } \\
\text { yok olacak. }\end{array}$ & $\begin{array}{l}\text { 9. ve bağadirlarin } \\
\text { qapilmiš olurlar } \\
\text { ey Tēmān kiši } \\
\text { içun } \\
\text { kesilmiš olur } \\
\text { dağindan `Esav nin } \\
\text { olum }^{20} \text { den. }\end{array}$ & $\begin{array}{l}\text { 9. da-sinigirlar } \\
\text { bagațirlarig } \\
\text { Tēmānanig } \\
\text { ucun } \\
\text { kesilgay kiši } \\
\text { țağindan ‘Esav nig } \\
\text { oldirmakțan. }\end{array}$ & נימוריך \\
\hline $\begin{array}{l}\text { 10. Yakup } \\
\text { soyundan gelen } \\
\text { kardeşlerine } \\
\text { Yaptığın } \\
\text { zorbalıktan } \\
\text { ötürü } \\
\text { utanca } \\
\text { boğulacak } \\
\text { ve sonsuza dek } \\
\text { yok olacaksın. }\end{array}$ & $\begin{array}{l}\text { 10. zulum luğundan } \\
\text { Ya'aqov qardašinin } \\
\text { ortsun }^{21} \text { seni } \\
\text { utanmaq } \\
\text { ve kesilsin } \\
\text { dunya adeq. }\end{array}$ & $\begin{array}{l}\text { 10. avanligindan } \\
\text { qardašig } \\
\text { Ya'aqov nig } \\
\text { yakar seni } \\
\text { uyațliq } \\
\text { da-kesilirsin } \\
\text { dunyaga degin. }\end{array}$ & מחמס \\
\hline
\end{tabular}

${ }^{20}$ The front pronunciation is not expressed.

${ }^{21}$ As above. 


11. Çünkü
yabancılar
onların malını
mülkünü
yağmaladıkları gün
uzakta durup
seyrettin.
Öteki uluslar
kapılarından içeri
girip
Yeruşalim için kura
çektiklerinde
Sen de
onlardan biri gibi
davrandın.

\begin{tabular}{|l|l|} 
11. durdunun & 11. țurgan \\
gunde qaršidan & kunigda qaršidan \\
gutÿurur'2 ediler & yațlar \\
yyesirler quvvetini & malin \\
ve yabancilarin & da-yațlar \\
girer ediler & kildilar \\
qapi larindan & qabiqlarina \\
ve atar ediler qur'a & da-Yerušalayim \\
Yerušalayim uzerine & usțuna \\
dahi sensin & țašladilar cek \\
biri gibi olardan. & dagin sen \\
& bir gibi alardan. \\
&
\end{tabular}

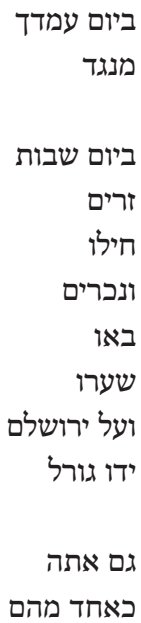

12. ve gormedin

gununde

qardašinin

gunde ki oldu

yabanciliği

ve sevinmedin

evladlarina

Yehudah nin gununde qayyibliqlarinin

ve buyyutmedin

ağzini

gununde siqletin ${ }^{23}$.

\section{2. da-baqmagin}

kuninda

qardašignig

yat bulgan

kuninda

da-sevinmagin

ugranlari ${ }^{24}$ ucun

Yehudah nig

țas bulgan

kunlarinda

da-ulgayțmagin

agzigni

kuninda țarliqnig.
ואל תרא

ביום

אחיך

ביום נכרו

ואל

תשמח

לבני תשמח

יהודה

ביום

אבדם

ואל תגדל

פיד

ביום צרה פיף

${ }^{22}$ As above.

${ }^{23}$ Compare the Turkish-Christian version; this is the second example of parallelism in the choice of roots.

${ }^{24}$ A misprint for uglanlari? 


\begin{tabular}{|c|c|c|c|}
\hline $\begin{array}{l}\text { 13. Halkım felakete } \\
\text { uğradığı gün Kente } \\
\text { girmemeliydin, } \\
\text { O gün halkımın } \\
\text { uğradığı kötülükten } \\
\text { zevk almamalı, } \\
\text { malını mülkünü } \\
\text { ele geçirmeye } \\
\text { kalkmamalıydın. }\end{array}$ & $\begin{array}{l}\text { 13. girmedin } \\
\text { qapisinda } \\
\text { milletimin } \\
\text { gununde } \\
\text { siniqliqlarin } \\
\text { gormedin } \\
\text { dahi sen } \\
\text { fenaliğinda } \\
\text { gununde } \\
\text { siniqliğinin } \\
\text { ve uzatmadin } \\
\text { elini }{ }^{25} \\
\text { malinda } \\
\text { gununde } \\
\text { siniqliğinin. }\end{array}$ & $\begin{array}{l}\text { 13. kelmagin } \\
\text { qabigina } \\
\text { ulusimig } \\
\text { kuninda } \\
\text { siniqliqlarinig } \\
\text { baqmagin } \\
\text { dagin sen } \\
\text { yamanligina } \\
\text { kuninda } \\
\text { siniqliginig } \\
\text { da-qol sunmagin } \\
\text { malina } \\
\text { kuninda } \\
\text { siniqliginig. }\end{array}$ & 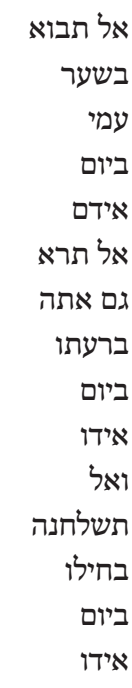 \\
\hline $\begin{array}{l}\text { 14. Kaçmaya } \\
\text { çalışanları } \\
\text { öldürmek için } \\
\text { yol ağzında } \\
\text { durmamalı, } \\
\text { o sıkıntılı } \\
\text { günde } \\
\text { kurtulanları } \\
\text { düşmana teslim } \\
\text { etmemeliydin. }\end{array}$ & $\begin{array}{l}\text { 14. ve durmadin } \\
\text { ol ayrilirmaqta } \\
\text { kesme } \\
\text { qurtulmušlarini } \\
\text { ve teslim itmedin } \\
\text { qalmišlarini } \\
\text { gununde siqletin. }\end{array}$ & $\begin{array}{l}\text { 14. da-țurmagin } \\
\text { ol buzuq usțuna } \\
\text { kesma } \\
\text { qacqinlarin } \\
\text { da-cigara barmagin } \\
\text { qaldiqlarin } \\
\text { kuninda țarliqnig. }\end{array}$ & כ' הפרק בית \\
\hline
\end{tabular}

${ }^{25}$ Actually, this word for "hand" does not appear in the Hebrew text; compare the TurkishChristian and the Gözleve Translation. 


15. RAB'bin bütün
ulusları
yargılayacağı gün
yaklaştı. Ey Edom,
ne yaptıysan sana
da aynısı yapılacak.
Yaptıkların kendi
başına gelecek.

16. Ey Yahudalılar,
kutsal dağımda
nasıl içtiyseniz,

bütün uluslar da öyle içecekler.

İçip içip yok olacaklar, hiç var olmamış gibi”.

17. Ama
kurtulanlar Siyon
Dağı'nda
toplanacak ve
orası kutsal
olacak. Yakup
soyu da mirasına
kavuşacak.

15. zire yaqin dir gunu Ya nin cumle ol milletler uzerine nasil ki qildin oyyle qilinir sana goremesin doner bašina.

16. ki nice içtiniz 'aziz dağim ozerine oyyle içerler cumle ol millet ler daim ve içerler ve olurler ve olurlar olmazinlar gibi.

17. ve dağinda

Ciyon nin olur qurtuluš ve olur qodeš ve evi Yaaqov nin meraslarlar merasçilari.
15. ki yuvuqțir kuni YWY nig jumla ol uluslar usțuna necik-ki qildig alay qilinir saga kuluvig qayțir bašiga.

$$
\begin{aligned}
& \text { כי קרוב } \\
& \text { יום ה' } \\
& \text { על כל יום } \\
& \text { הגוים }
\end{aligned}
$$

16. ki necik-ki icțigiz ayruksi țağim ucun

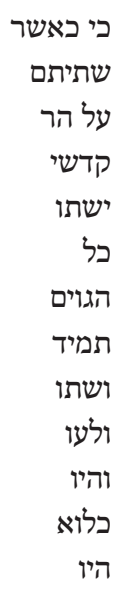




\begin{tabular}{|c|c|c|c|}
\hline $\begin{array}{l}\text { 18. "Yakup soyu } \\
\text { ateş, Yusuf soyu } \\
\text { alev, Esav soyu } \\
\text { anız olacak. Onları } \\
\text { yakıp yok } \\
\text { edecekler. Esav } \\
\text { soyundan kurtulan } \\
\text { olmayacak". RAB } \\
\text { böyle diyor. }\end{array}$ & $\begin{array}{l}\text { 18. ve evi } \\
\text { Ya'aqov nin olur } \\
\text { ateš } \\
\text { ve evi } \\
\text { Yosef nin } \\
\text { alef } \\
\text { ve evi } \\
\text { 'Esav nin } \\
\text { samana } \\
\text { ve yanarlar } \\
\text { olarda } \\
\text { ve yaqarlar olari } \\
\text { ve olmaz } \\
\text { qaldiq } \\
\text { evine } \\
\text { 'Esav nin } \\
\text { ki Ya soyyledi. }\end{array}$ & 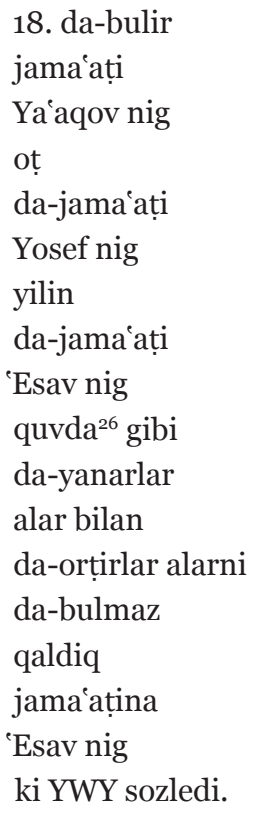 & לית וביה ובית ובית \\
\hline $\begin{array}{l}\text { 19. Yahudalılar'dan } \\
\text { Negev halkı } \\
\text { Esav'ın dağlarını; } \\
\text { Şefela halkı Filist } \\
\text { bölgesini; } \\
\text { Yahudalılar'ın } \\
\text { tümü Efrayim ve } \\
\text { Samiriye } \\
\text { topraklarını; } \\
\text { Benyaminliler } \\
\text { Gilat'ı mülk } \\
\text { edinecekler. }\end{array}$ & $\begin{array}{l}\text { 19. ve kišileri } \\
\text { ki cenub tÿarafin } \\
\text { meraslarlar } \\
\text { daği `Esav nin } \\
\text { ve ol alçaqlanmiši } \\
\text { Pelištim lere } \\
\text { ve meraslar lar } \\
\text { tÿarlasin } \\
\text { 'Efrayim nin } \\
\text { ve tÿarlasin } \\
\text { Šomeron nin } \\
\text { ve Binyamin } \\
\text { ol Gil'ad ni² }\end{array}$ & $\begin{array}{l}\text { 19. da meraslarlar } \\
\text { ol xušlikni } \\
\text { țağin `Esav nig } \\
\text { da-ol alçaq yerni } \\
\text { Pelištim larni } \\
\text { da meraslar lar } \\
\text { tuzun } \\
\text { 'Efrayim nig } \\
\text { da țuzun } \\
\text { Šomeron nig } \\
\text { ve Binyamin } \\
\text { ol Gil'ad ni }{ }^{28} \text {. }\end{array}$ & שי \\
\hline
\end{tabular}

${ }_{26}$ This is a misprint for * quvra, see APPENDIX I.

${ }_{27}$ Note the Qipčaq-like Accusative suffix

${ }^{28}$ As above. 


\begin{tabular}{|c|c|c|c|}
\hline $\begin{array}{l}\text { 20. Kenan'dan } \\
\text { sürülmüsş olan } \\
\text { İsrailli } \\
\text { savaşçlar } \\
\text { Sarefat'a kadar } \\
\text { uzanan } \\
\text { toprakları, } \\
\text { Sefarat'taki } \\
\text { Yeruşalimli } \\
\text { sürgünler } \\
\text { de Negev'deki } \\
\text { kentleri mülk } \\
\text { edinecekler. }\end{array}$ & $\begin{array}{l}\text { 20. ve yesirliği } \\
\text { bu ol quvvetin } \\
\text { evladlarindan } \\
\text { Yisrael nin } \\
\text { ki } \\
\text { Kena`anim } \\
\text { Cārefat edeq } \\
\text { ve yesirliğin } \\
\text { Yerušalayim nin } \\
\text { ki } \\
\text { Sefarad tÿa } \\
\text { maraslarlar } \\
\text { šeherleri } \\
\text { ol qibla nin. }\end{array}$ & $\begin{array}{l}\text { 20. ve yesiri } \\
\text { ušbu ceriv nig } \\
\text { oglanlarinig } \\
\text { Yisra'el nig } \\
\text { ki } \\
\text { Kena'anlilar } \\
\text { Cārefat qa degin } \\
\text { da yesirli } \\
\text { Yerušalayim nig } \\
\text { ki } \\
\text { Sefarad da } \\
\text { maraslarlar } \\
\text { šaharlarin } \\
\text { ol xušliknig. }\end{array}$ & 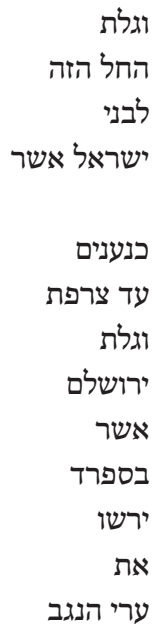 \\
\hline $\begin{array}{l}\text { 21. Halkı } \\
\text { kurtaranlar } \\
\text { Esav'ın dağlarını } \\
\text { yönetimleri altına } \\
\text { almak için Siyon } \\
\text { Dağı'na çıkacaklar } \\
\text { ve egemenlik } \\
\text { RAB'bin olacak. }\end{array}$ & $\begin{array}{l}\text { 21. ve çiqarlar } \\
\text { qurtaricilar } \\
\text { dağinda Ciyon yin } \\
\text { šerāaatÿ itme } \\
\text { dağin nin 'Esav nin } \\
\text { ve ol padišahliq } \\
\text { olur Ya dan. }\end{array}$ & $\begin{array}{l}\text { 21. ve çigarlar } \\
\text { qutqarywcilar } \\
\text { țağinda Ciyon nig } \\
\text { šarāaatÿ ețma } \\
\text { țağina Esav nig } \\
\text { da-bolir } \\
\text { YWY ga } \\
\text { ol xanliq. }\end{array}$ & הושלו \\
\hline
\end{tabular}

The text of Obadiah in the Osnabrück MS is a copy, as is evident from the omission of words (Obad 1). We encounter reflections of interaction between the Missionary text of the Bible translation into Turkish and the Karaite translations (Obad 3, 12).

There is no distinction between $q / k$ (kucuq, Obad 2; okseq, Obad 3; oqseqlensen, Obad 4), as is normal in Constantinople and, probably, in the Southern Coast of the Crimea. ${ }^{29}$ Oğuz and Qipčaq Dative and Accusative suffixes (Obad 1, 19) are used interchangeably, with the Oğuz variants being the majority. This is quite normal for an author with a Crimean background; mixing Oğuz and

${ }^{29}$ My friend and neighbor, Dr. Chernin, has observed that the Qrımčaqs did not distinguish between these two consonants in Hebrew, while they do in their own Turkic language. Cf. CHERnin 2000/2001: 31-38. 
Qipčaq was characteristic of Muslim, Jewish, and Christian texts written in the Crimea, with the prevalence of Oğuz or Qıpčaq elements depending on the author, his style at this particular moment, or his presumed audience; in addition, plain dialectal slips were made. These texts found in the MS may have been composed either in the Crimea (apparently, in the Southern part of the Peninsula, most probably in the largest Karaite center on the Crimean Southern Coast, Feodosija), or in Constantinople, by a Crimean Karaite from elsewhere who tried to write Turkish. Here arises the very interesting question of the existence (or non-existence) of a unified Turkic written language amongst the Karaites in the Crimea in the $19^{\text {th }}$ century. My own gut-feeling is that there was not any, as there was no common written language amongst the Crimean Muslims, prior to Ismail Gasprinski (which was not a "Crimean" language, either).

No expression of front-back vowel variants was made, ${ }^{30}$ as is evident from the use of emphatic and laryngeal letters in the words with front pronunciation (kucuq, Obad 2; okseq, Obad 3; guțurur, Obad 11).

We can therefore see that a late- $19^{\text {th }}$-century Karaite in Istanbul (or Keffe / Feodosija?) was translating Biblical texts into Constantinople (or Keffe?) Turkish, slightly tinted by Qıpčaq, but into undeniably Turkish, using the same translation techniques used by the $17^{\text {th }}$ and $18^{\text {th }}$ centuries' Karaite translators into Karaim, ${ }^{31}$ by Avraham Firkowicz who used an artificial Turkish-cum-Karaim language in the early 1830 s, and, as I am going to demonstrate in APPENDIX III, by the early $20^{\text {th }}$ century Rabbanite Qrımčaqs (who were copying the Karaim techniques).

A comparison one would make with the highly archaic Karaim language of the Gözleve edition of 1841 is also quite telling. Thus, what was frequently seen as trademarks of the Karaim language, are, possibly, merely characteristics of a literary genre.

\section{APPENDIX I}

Here I provide notes on some interesting words found in the Gözleve Translation of Obadiah, basing myself on Baskakov, N. A., A. Zajončkovskij, S. M. Šapšal (eds.). 1974. Karaimsko-russko-pol'skij slovar'. Moskva: Russkij Jazyk.

\footnotetext{
$3^{\circ}$ On this phenomenon in Turkish as used by Jews, cf. JANkowski 2012: 257-264.

${ }^{31}$ See SHaPIRA 2013: 133-198.
} 


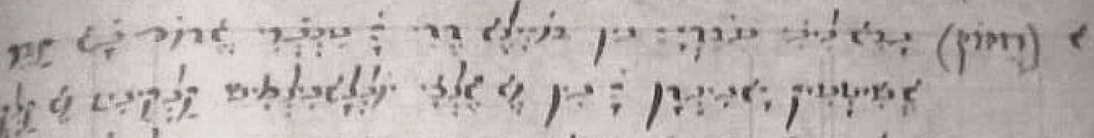

\section{(1)}

2. 790

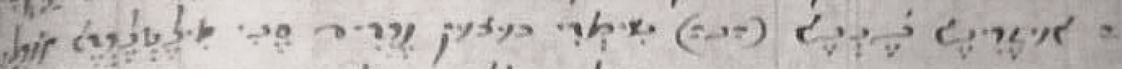

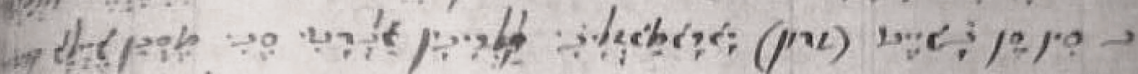

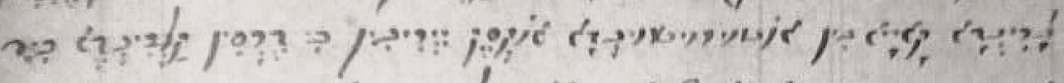

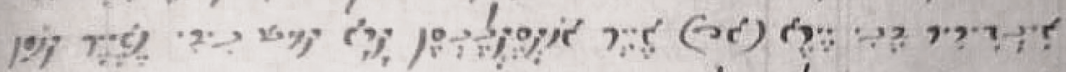

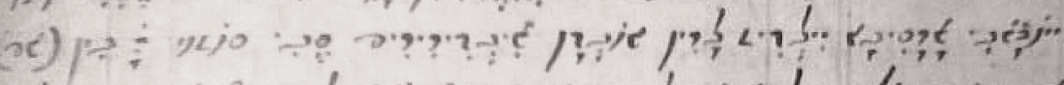

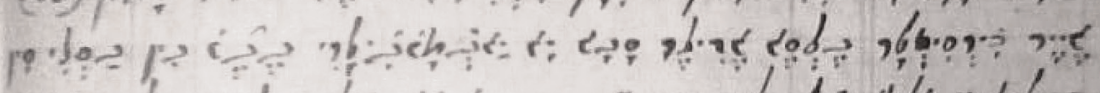

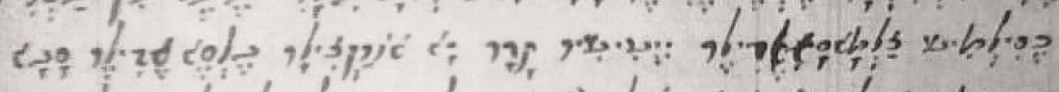

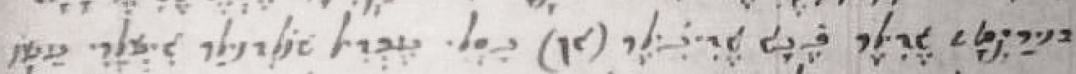

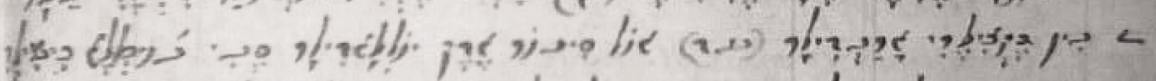

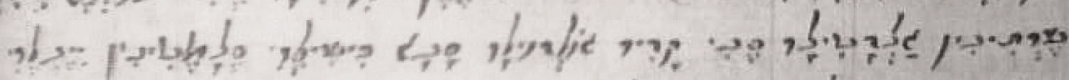

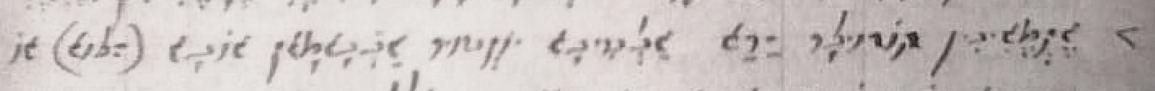

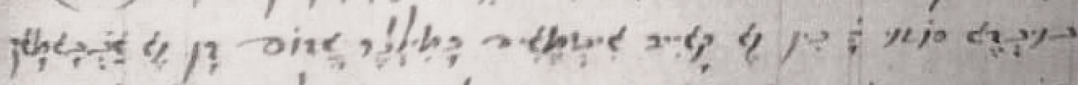

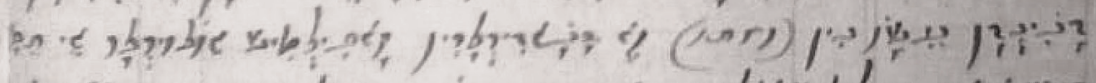

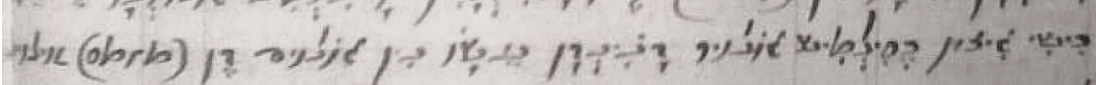

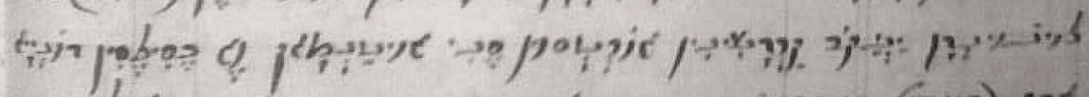
pl:

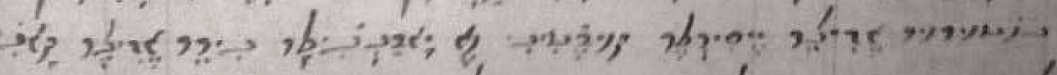

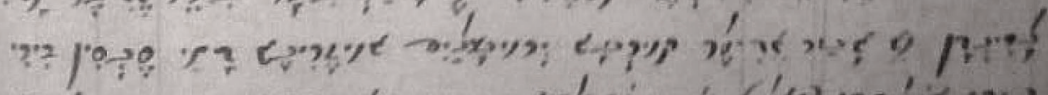
? 6y

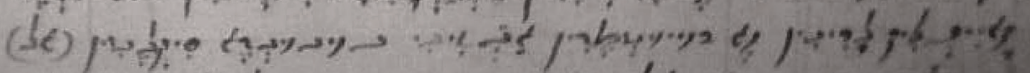

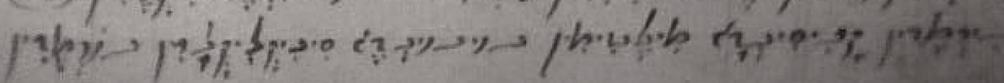


$=-29,5$

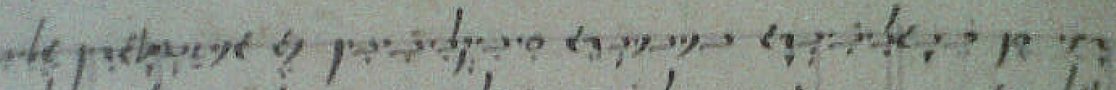
dyjleyt?

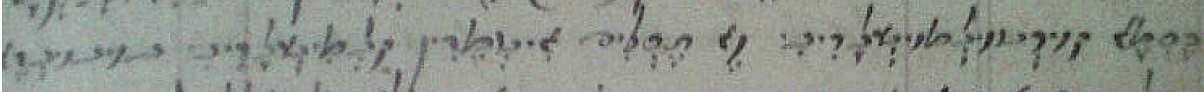
sumec to

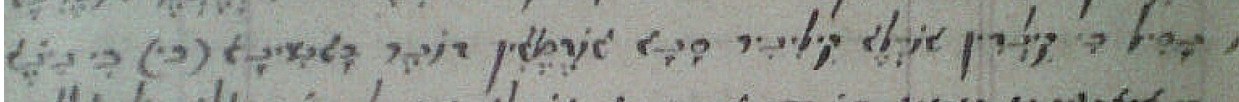

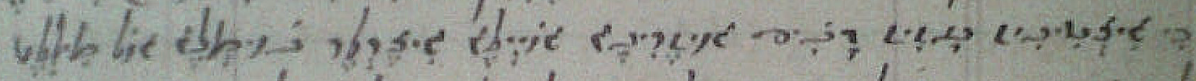

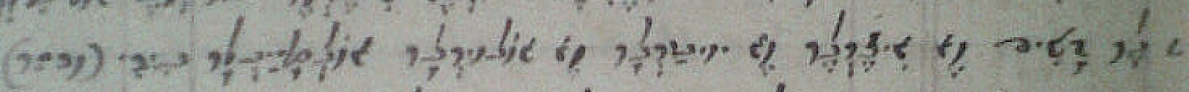
$\mu$ in

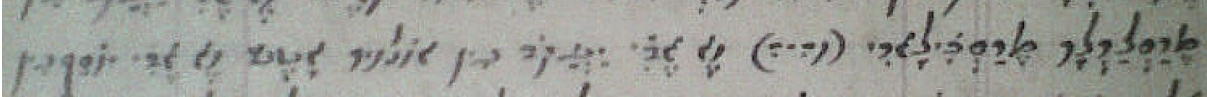

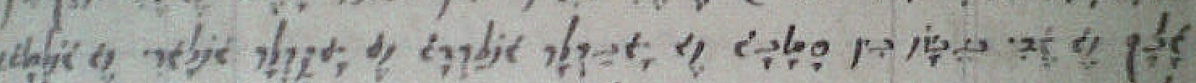

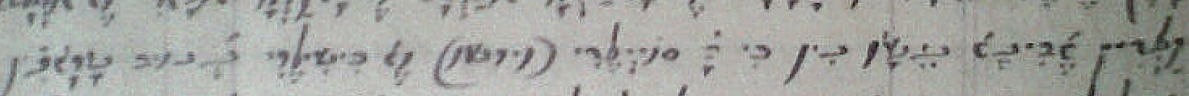

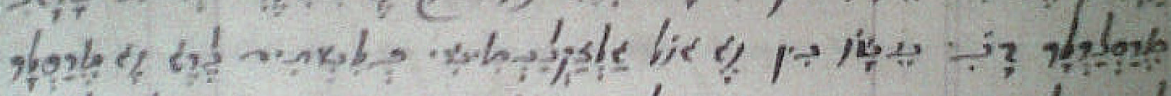

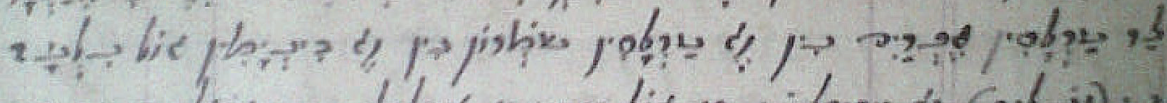

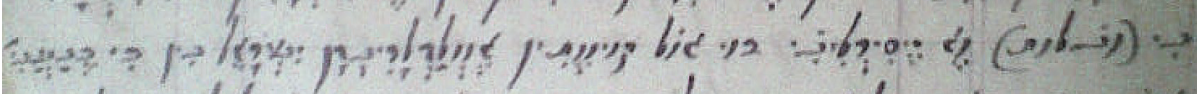

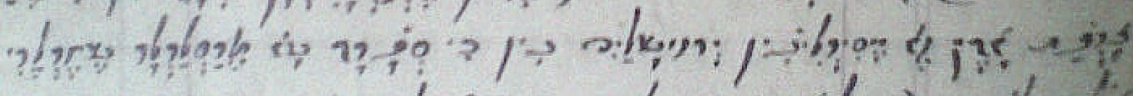

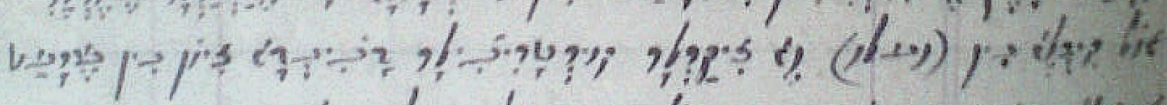

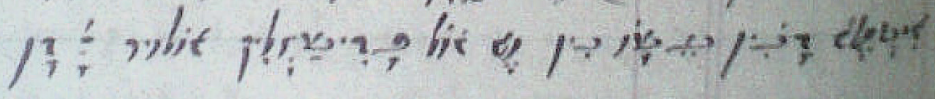

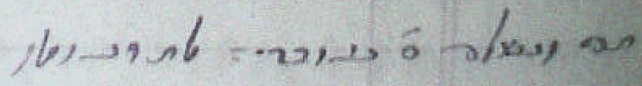




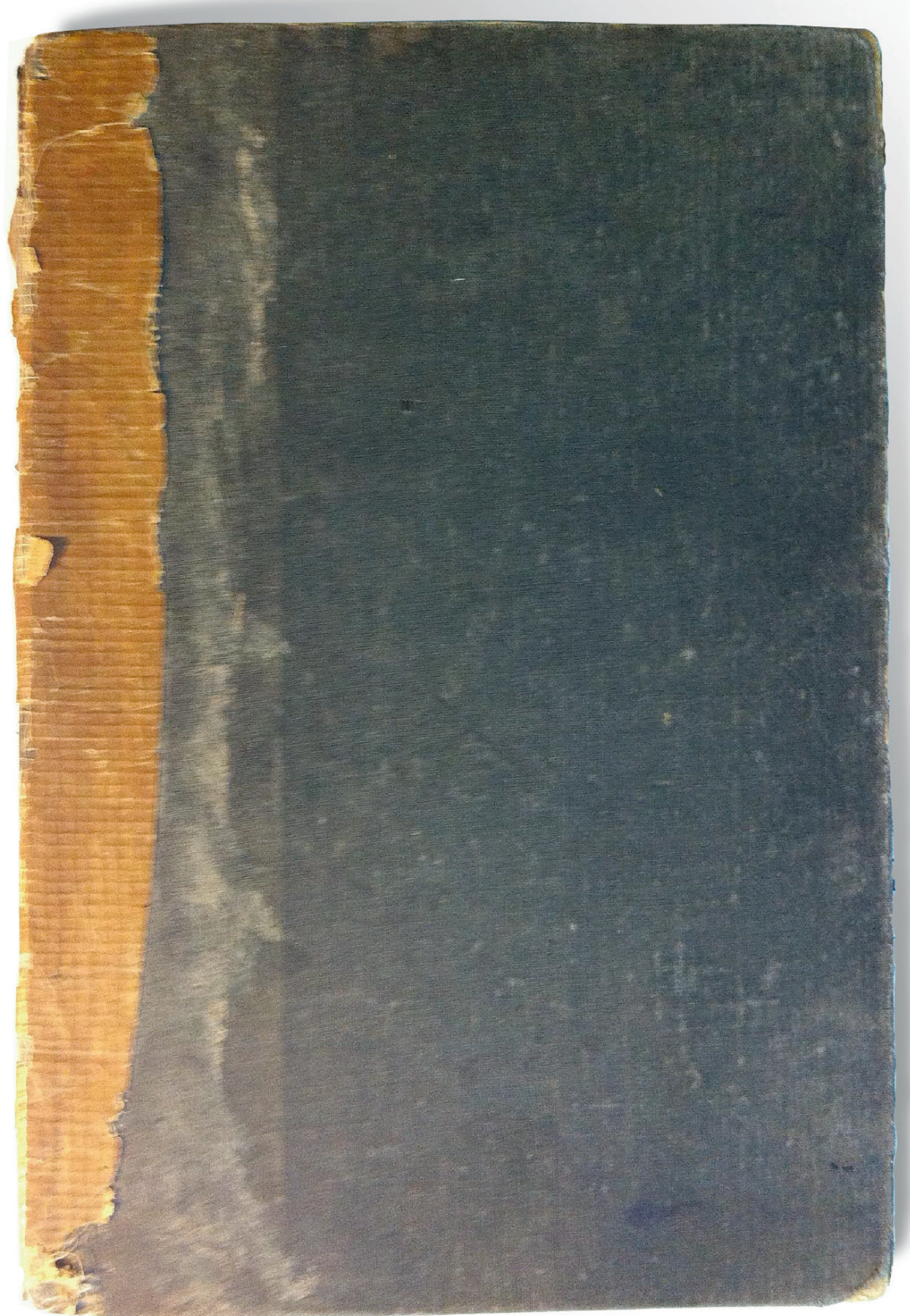

The cover of the MS. 
alçaq yer, השפלה, Turkish alçaqlanmiš; for alçaq, see Baskakov, Zajončkovskij, Šapšal 1974 (henceforth: the dictionary), p. 66 (niski).

avanlig, חמס, Turkish zulum-luğ; according to the dictionary, p. 39, tk avan (грех, проступок / grzech, występek) is of Hebrew origin (apparently, from 'âwōn); this is likely, though the orthography, with an aleph, looks weird; аванлык h, беззаконие, произвол / besprawie, samowola; подлость / podłość; etc., pp. 39-40.

borla coplavcilar, בצרים, Turkish oraqçilar; thk borla = виноградник / winnica; виноградная кисть, виноград; изюм / winne grono, winogrona / rodzynki, p. 131. coplavci / čoplavči is not attested in the dictionary, but see p. 631, k čopla-; cf. p. 538, thk topla-; p. 614, h copla-; p. 628, t čopla-.

buzuq, פרק, Turkish ayrilirmaq; h buzuk = испорченный, zepsuty; разрушенный, zniszczony, p. 137. The GT (Gözleve Translation) and OT (Osnabrück Translation) have here different understandings of Hebrew PRQ.

cayaliğg זדון, Turkish yaramaliğ; k čayalyk = надменность, заносчивость; гордость, высокомерие, спесь / pycha, duma; zarozumiałość, wyniosłość; дерзость; упорство / zuchwałość; upór; злонамеренность / szkodliwość; необузданность / niepowściągliwość, p. 621, and similar forms in the Halicz and Troki dialects.

caypal-,ע"ע, Turkish öl-; tk čaypal- = tk быть испорченным, портиться / być zepsutym, psuć się; / пропадать, гибнуть / ginąć; / развращаться, быть развращённым / psuć się, być zepsutym; обманывать / oszukiwać, p. 621, and similar forms in the Halicz and Troki dialects.

cek, גורל, Turkish qur'a; k ček = жребий / los; предел, граница / granica, kres, p. 640; compare t ček on p. 626, where only the meaning "border" is given (an evident mistake by Shapshal or Zajączkowski, demonstrating thus limits of Hebrew proficiency of one of them) and similar forms in the Halicz and Troki dialects.

cerțimlar, עללות, Turkish fena ediniler; k čerțim = малая гроздь, малая кисть (винограда) / mała kiść (winogron), p. 641. The author of the OT committed here an error in his Hebrew.

elli, ציר, Turkish elçi; there is no elli in the dictionary, but this form might be a misprint in the GT.

kuluv, גמול, Turkish goreme $={ }^{*}$ göreme; kuluv seems to be connected to $\mathrm{h}$ колувцу [kołuwcu M] проситель / petent ср. колувчу. колувчу t [kołuvću K] 
проситель / petent; ср. колувцу, p. 331. I doubt the meaning ascribed by the dictionary to these words.

qutqarywci, מושיע, Turkish qurtarici; k qutqar- (къуткъар-) спасать, избавлять; освобождать / ocalać, wybawiać, wyzwalać; k къуткъарывчы, спаситель, избавитель / zbawiciel; etc., p. 376, cf. pp. 350-351.

quțlmaq, פליטה, Turkish qurtuluš; k къутул-, избавляться, спасаться, освобождаться / оcalać się, wybawiać się, wyzwalać się; cf. k кутул-, къутыл-; k къутулуш, избавление, спасение, освобождение / wybawienie, oswobodzenie, p. 376.

quvda, קש, Turkish saman; quvda is a misprint for $\mathrm{k}{ }^{*} q u v r a$, солома; сено / |słoma; siano, p. 373.

saqlanmišlari, מצפניו, Turkish beqçileri; k сакълан-, скрываться, прятаться / ukrywać się, chować się; cf. k сакълангъан k, неизменный, непреложный / niezmieny; k сакъланмыш / sakłanmyś, спрятанный / ukryty, p. 462.

sinig-, חת"ת, Tukish qapilmiš olurlar, and siniqliq, איד, Turkish siniqliq; th synykma, сынык, ломаться / łamać się; падать духом, мучиться / upadać na duchu, męczyć się; synykłyk, обломок / odłamek; перелом / złamanie; слабость; боязнь; раскаяние / słabość; bojaźń; skrucha; etc., p. 493.

tarliq, צרה, Turkish siqlet; тарлык A [tarłyk M] беда, нужда / bieda, nędza; мучение, испытание; беда, bieda, męczenie, doświadczenie; etc., p. 515 .

țalovci, שודד, Turkish yağmağı; thk талав, грабёж, разбой, опустошение; уничтожение / rabunek, rozbój, spustoszenie; zniszczenie; награбленное, добыча / zdobycz, lup; h талавцу, разбойник, грабитель / łupieżca, rabuś; t талавчу, талавчы, талувчы, разбойник, грабитель, опустошитель / łupieżca, rabuś, pustoszyciel; k талавчы, грабитель / łupieżca; etc., p. 507.

țințildilar, נחפשו, Turkish tebdil oldular; k тынт-, обыскивать; исследовать / rewidować; badać, studiować.; k тынтув, обыск / rewizja; p. 557.

tas, אב"ד, Turkish qayyib; thk tas = уничтожение, исчезновение / zniszczenie, zniknięcię; etc., p. 516.

tuz, שדה, Turkish tarla; țuz = k tüz (compare the "very non-Crimean" spelling with a $t$ in word with a front vowel) = равнина, поле; долина / równina, pole; dolina, p. 552, and similar forms. 
ugdilar, גנבים, Turkish xirsizlar; ugdilar is apparently a misprint for *ugrilar, "thieves"; the word is absent from the dictionary, but cf. forms on p. 580 . uklilar, חכמים, Turkish kāmiller; apparently, from Arabic 'aql, but threre is no $u k l i$ in the dictionary. Cf. Turkish of Turkey ukalâ.

uruš, מלחמה, Turkish ceng; tk uruš = война, борьба, сражение, битва / wojna, walka, bitwa, p. 582, and similar form in the Halicz dialect.

xušlik, נגב, Turkish qibla, cenub țarafi; xušlik, apparently, from a Persian loan word meaning "dry", is not found in the dictionary.

yilin, להבה, Turkish alef [*alev]; there is no yilin / jylyn in the dictionary.

\section{APPENDIX II}

\section{RUTH}

I am giving here three translations of Chapter 1 of the Book of Ruth.

\section{I}

The text to the left is taken from the new Judeo-Turkish manuscript from Germany; this text is, basically, Oğuz / "Ottoman”-Turkish / South-Western Turkic, with some Qıpčaq / Crimean-Tatar features (dağın / dahın, ilen).

\section{II}

The text in the middle is excerpts from the Turkic translation of Ruth made for the Crimean-Tatar-speaking Qrımčaq Rabbanite Jews at the very end of the $19^{\text {th }}$ century, at the command of R. Hizqiyahu Medini (1832-1904). R. Medini was an Ottoman subject born in Hebron in the Ottoman Judaea, and he ordered to translate the so-called Second Translation of the Scroll of Ruth from Aramaic into the best Turkish language possible for his Qrımčaq Rabbanite community (whose language he did not speak). The book was published in 1906 in Petrokov, translated by Nissim Levi Čexčir. Yanbay and Erdal published a scientific edition of the text; ${ }^{22}$ in their introduction, they wrote (p. 2): "The language of our source cannot be taken identical with Krimchak ...”.

${ }^{32}$ IANbay \& ERdal 1998: 1-53. 
The original Aramaic Targum of Ruth or the Second Translation of the Scroll of Ruth is a very long midrashic text organized around the verses of the Book of Ruth. It was written in Galilean Aramaic, abundant in both Greek and Middle Iranian words. The text was widely read in many Rabbanite communities, for it contains much aggadic or folkloric material and suited the tastes of women and the less-educated. When the knowledge of Aramaic diminished, translations were made from Aramaic into vernaculars, one of them into a language suitable for the Crimean-Tatar-speaking Qrımčaq Rabbanite Jews. I designate the language of the Crimean-Turkic translation as "a language suitable for the Crimean-Tatar-speaking Qrımčaq Rabbanite Jews", because I have no a better name for it: clearly, it was not the language they spoke; this language was obviously supposed to be understood by them. I claim that this literary language of the Crimean-Tatar-speaking Qrımčaq Rabbanite Jews was modelled on the language of Karaite/Karaim Bible translations, which was seen by the Qrımčaq Rabbanite Jews as a language of prestige. We do not have many texts representing the way the Qrımčaqs spoke, for their folkloric texts were written down in the language of their neighbours; in Appendix III, I will provide a short specimen of a Qrımčaq Bible translation.

\section{III}

The right column is taken from a manuscript previously belonging to the Elyashevich-Babadjan (Babacan) family. My old friend Dr. Maxim Hammal, who had introduced me to this fascinating Karaite family in Moscow and through whom I was lucky to make copies of parts of this important manuscript, announced me that this MS was gone. In the best case scenario, the family gave it out to the Lithuanian Karaite community.

What we can learn from just having had a glance at the page - and one has no need to know any Turkic - is that the Karaite text from Troki (?) agrees with the first and the second columns. 


\section{Megillath Ruth In Three Turkic Translations}

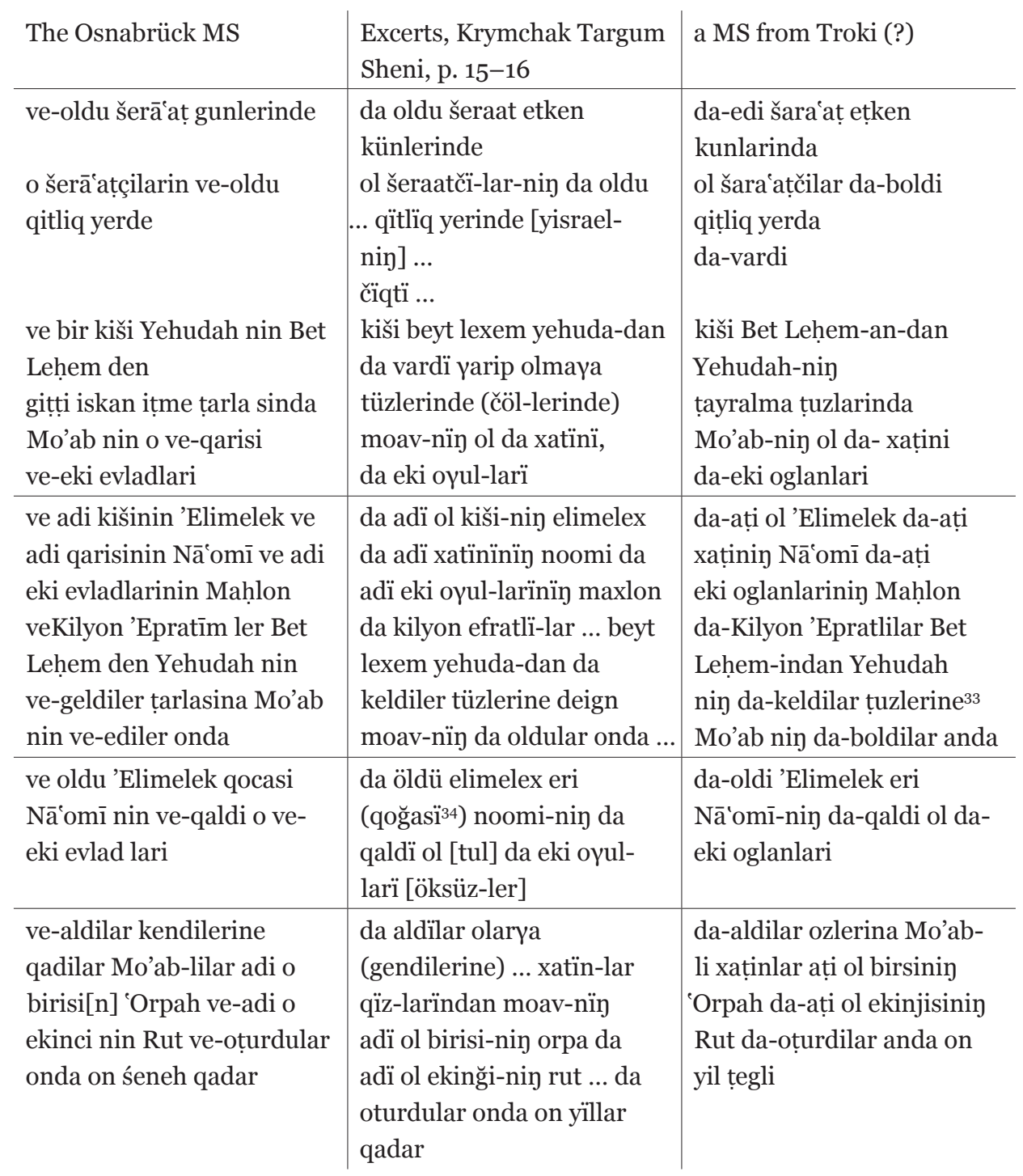

33 The final suffix -ne written above the line.

${ }^{34}$ In Yanbay-Erdal, $\breve{g}=$ Modern Turkish $c$. 


\begin{tabular}{|c|c|c|}
\hline $\begin{array}{l}\text { ve-olduler dahi ekisi } \\
\text { Mahlon ve-Kilyon ve-qaldi } \\
\text { o qari eki evladlarindan ve- } \\
\text { qocasindan }\end{array}$ & $\begin{array}{l}\text { da-öldüler [h]em ekileri } \\
\text { maxlon da kilyon ... da qaldï } \\
\text { ol xatïn mahrïm eki oyul- } \\
\text { larïndan da tul erinden }\end{array}$ & $\begin{array}{l}\text { da-oldilar danin ekisi } \\
\text { Maḥlon da-Kilyon da-qaldi } \\
\text { ol xațin eki oglanlarindan } \\
\text { da-erinden }\end{array}$ \\
\hline $\begin{array}{l}\text { ve-qalqți o ve-gelinleri ve- } \\
\text { dondu țarlasindan Mo’ab } \\
\text { nin zira ešițti țarlasinda } \\
\text { Mo'ab nin ki sag/c/y/indi } \\
\text { Ya milețini verme onlara } \\
\text { eqmeq }\end{array}$ & $\begin{array}{l}\text { da turdi ol da kelin-leri } \\
\text { da qayttï tüzlerinden } \\
\text { moav-nïy ki müğde } 35-l e n d i \\
\text { tüzünde moav-nï̄ ... ki } \\
\text { aydï adonay xalqïnï ... } \\
\text { vermege olarya ökmek }\end{array}$ & $\begin{array}{l}\text { da-țurdi ol da-kelinlari da- } \\
\text { qayțți țuzlerindan Mo'ab } \\
\text { nị ki ešițti țuzlerinda } \\
\text { Mo'ab nin ki sagindi YWY } \\
\text { šol ulusin verma alarna } \\
\text { oțmak }{ }^{36}\end{array}$ \\
\hline $\begin{array}{l}\text { ve-çiqți o yerdan ki edi } \\
\text { onda ve-eki gelinleri onun } \\
\text { ilen ve-gitțiler yolda donme } \\
\text { yerine Yehudah nin }\end{array}$ & $\begin{array}{l}\text { da čiqtï ol yerden ki oldu } \\
\text { onda da eki kelinleri } \\
\text { barabarïna da yürüdüler } \\
\text { yolda qaytmaya yerine } \\
\text { yehuda-nïn }\end{array}$ & $\begin{array}{l}\text { da-ciqți ol yerdan ki edi } \\
\text { anda da-eki kelinlari } \\
\text { birgasina da vardilar } \\
\text { yol bilan qayțma yerina } \\
\text { Yehudah niy }\end{array}$ \\
\hline $\begin{array}{l}\text { ve-dedi Nāomī eki } \\
\text { gelinlerine variniz donunuz } \\
\text { her bir qari evine anasinin } \\
\text { qilsin Ya sizin eyle } \\
\text { merhāmeț nasil ki yaptiniz } \\
\text { oluler bilen ve-benim ilen }\end{array}$ & $\begin{array}{l}\text { da eytti noomi eki kelin- } \\
\text { lerine varïyïz qaytïyïz xatïn } \\
\text { evine anasïnïn etsin adonay } \\
\text { barabarïnïzya yaxšilïq } \\
\text { nečik ki ettiniz, } \\
\text { ol ölgen erleriniz ilen ... da } \\
\text { barabarïma }\end{array}$ & $\begin{array}{l}\text { da-ayțti Nāomī eki } \\
\text { kelinlarina bariniz qayținiz } \\
\text { xațin evina anasinin qilgay } \\
\text { YWY birnayizga šagawaț } \\
\text { ol olular bilan da-birnama }\end{array}$ \\
\hline $\begin{array}{l}\text { versin Ya size ve-bulasiz } \\
\text { rāhatliq her bir qari evine } \\
\text { qocasinin ve-optu olari ve } \\
\text { qaldirdilar seslerini ve- } \\
\text { ayladilar }\end{array}$ & $\begin{array}{l}\text { versin adonay sizge ... da } \\
\text { tapqaysïz rahatlïq er beriniz } \\
\text { da biriniz evinde erinin da } \\
\text { öptü olarnï da köterdilar } \\
\text { seslerini da yïyladillar }\end{array}$ & $\begin{array}{l}\text { birgay YWY sizga da- } \\
\text { țapqaysiz țancliq har xațin } \\
\text { evinda erinin da-opti alarni } \\
\text { da-koțardilar avazlarin da- } \\
\text { yayladilar }\end{array}$ \\
\hline $\begin{array}{l}\text { ve-dediler ona ki senin ile } \\
\text { donelim mileține }\end{array}$ & $\begin{array}{l}\text { da eyttiler ona, ... ki emme } \\
\text { barabarïna qaytïrbïz } \\
\text { xalqïna }\end{array}$ & $\begin{array}{l}\text { da-ayțțilar anar ki birnaya } \\
\text { qayțirmiz ulusina }\end{array}$ \\
\hline
\end{tabular}

ve-dedi Nāomī donunuz qizlarim neiçun gelirsiz benim ilen dahan varmi bana evladlar qursağimda ve-olsunlar size qocalara da eytti noomi, qaytïnïz qïzlarïm! ne üčün varïrsïz barabarïma. eger ajïz ... varmïdïr maya oyullar qursaqïm-da da olsunlar sizge erler-ge da-ayțtị Nāomī qayținiz qizlarim nučun barirsiz birnama daginemi mana oglanlar qursagimda dabolanilar sizga eranlarga

\footnotetext{
35 In Yanbay-Erdal, $\breve{g}=$ Modern Turkish $c$.
}

${ }^{36} k>t$, a Halicz shift? 


\begin{tabular}{|c|c|c|}
\hline $\begin{array}{l}\text { donunuz qizlarim gidiniz } \\
\text { zira extiyar oldum olmadan } \\
\text { qocana zira dedim vardir } \\
\text { bana omud dahi olsam } \\
\text { bu gece qocaya ve-dahi } \\
\text { doğursam oglanlar }\end{array}$ & $\begin{array}{l}\text { qaytïnïz qïzlarïm ... varïnïz } \\
\text { xalqïnïz-үa ki qartaydïm } \\
\text { olmaqtan evlengen erge } \\
\text { ki eytsem edi ... vardïr } \\
\text { maya ümüt em evlensem } \\
\text { edim bu geğe }{ }^{37} \text { erge da em } \\
\text { doүursam edim oүul-lar }\end{array}$ & $\begin{array}{l}\text { qayținiz qizlarim bariniz ki } \\
\text { qarțaydim bolmaqtan erga } \\
\text { ki ayțkay edim vardir maya } \\
\text { musanč dagin bolirmimi } \\
\text { bugača erga dadagin } \\
\text { dogurirmimi oglanlar }\end{array}$ \\
\hline $\begin{array}{l}\text { beklermisiz olar içun } \\
\text { hatțā ki buyyuq olurlar } \\
\text { aliqonurmusuz olar içun } \\
\text { olmamaya qocaya yoq } \\
\text { qizlarim zire aci bana } \\
\text { ğāyyeț sizden zire qudreți } \\
\text { anin çiqți benden }\end{array}$ & $\begin{array}{l}\text { belki olarya siz toqtayïrsïz } \\
\text { čaq ki öserler, xatïn kibik } \\
\text { ki toqtar kičkene biya-үa } \\
\text { evlenmege erge. eger olar } \\
\text { üčün siz otururmusïz } \\
\text { baylïlar olmamaq üčün } \\
\text { evlenfenler erge. yalvarmaq } \\
\text { ilen qïzlarïm! ağitmegeysiz } \\
\text { ğanïm-nï ki aği-dir mana } \\
\text { artïq sizden ki čïqtï mende } \\
\text { xïšïm alïndan yeya-nïn }\end{array}$ & $\begin{array}{l}\text { alargami mosanirsiz } \\
\text { daginča ki ulgaygaylar } \\
\text { alargami kečenersiz } \\
\text { bolmamaqqa erga yoq } \\
\text { qizlarim ki ači boldi maya } \\
\text { sizden artiq ki čiqți maya } \\
\text { xišim alïndan YWY-niy }\end{array}$ \\
\hline $\begin{array}{l}\text { ve-qaldirdilar seslerini ve } \\
\text { ağladilar dahin ve-opțu } \\
\text { Orpah qaynanasina ve-Rut } \\
\text { yapišți onun ilen }\end{array}$ & $\begin{array}{l}\text { da köterdiler seslerini da } \\
\text { yïүladïlar daa ... da öptü } \\
\text { orpa qaynanasïnï da rut } \\
\text { yapištï onda }\end{array}$ & $\begin{array}{l}\text { da-koțardilar avazlarin } \\
\text { da-yayladilar dagin da-opți } \\
\text { 'Orpah qaynanasin da-Rut } \\
\text { yapušți anar }\end{array}$ \\
\hline $\begin{array}{l}\text { ve-dedi Nāomī šimdi } \\
\text { dondu elțenin mileține } \\
\text { ve-Ṭanrisina don ardindan } \\
\text { elțeninin }\end{array}$ & $\begin{array}{l}\text { da ayttï, muna qayttï } \\
\text { kelindešin xalqïna da } \\
\text { avoda-zara-sïna qaytqïn } \\
\text { artina kelindešin-nin }\end{array}$ & $\begin{array}{l}\text { da-ayțți muna qayțți } \\
\text { kelindešin ulusina da- } \\
\text { Țenrisina qayțqin arțindan } \\
\text { kelindešinniy }\end{array}$ \\
\hline
\end{tabular}

ve-dedi Rut ricā ețmeyyesin bana buraqma ičun donmeyye ardindan zire nereyye varsan varirim venereyye qonsan qonirim milețin olur milețim veȚayrin Țayrim da ayttï rut, qaherletmegeysin meni tašlamaya seni qaytmaya ardïndan ... ğümle ne-ge ki varsan varayïm ... ğümle yerde ki qonsay qonayïm ... xalqïn olayïm ... tayrïy oldïr tạrïm da-ayțți Rut yalvarmanin mana kemišma seni qayțma arțindan ki qayda ța varsay vararmin da-qayda ki qonsay qonarmin ulusin ulusum da-Teyrin Teyrim

37 In Yanbay-Erdal, $\breve{g}=$ Modern Turkish $c$. 


\begin{tabular}{|c|c|c|}
\hline $\begin{array}{l}\text { nerede olupsan olupsam } \\
\text { ve-orada komulupum } \\
\text { boyyle qilsin Ya bana ve- } \\
\text { oyyle arțirsin andan ol } \\
\text { olum ayyirir arami ve-arani }\end{array}$ & $\begin{array}{l}\text { ğümle ne-ge ki ölsey öleyim } \\
\text {... da onda alayïm kömülgen } \\
\text {... bulay etsin maya adonay } \\
\text { da bulay arttïrsïn üstüme } \\
\text { ki ol ölüm olsun ayïryan } \\
\text { arama da araya }\end{array}$ & $\begin{array}{l}\text { qayda ki olsay olarmin } \\
\text { da-anda komulirmin bulay } \\
\text { qilgay YWY maya da-bulay } \\
\text { arțtirgay ki ol olum ayirir } \\
\text { arama da araya }\end{array}$ \\
\hline $\begin{array}{l}\text { ve-gordu ki keskindir o } \\
\text { gițme onun ilen ve-bazgečṭi } \\
\text { soyyleme ona }\end{array}$ & $\begin{array}{l}\text { da kördü ki küčeyir ol } \\
\text { varmaya barabarïna da } \\
\text { vazgečti söylemekten oya }\end{array}$ & $\begin{array}{l}\text { da-kordi ki kučaydir ol } \\
\text { varma birgasina da țayildi } \\
\text { sozlamakțan anar }\end{array}$ \\
\hline $\begin{array}{l}\text { ve-gițiler ekisi berāber } \\
\text { gelincādeq } \\
\text { Bet Lehem ve-oldu geldiq } \\
\text { leri gibi Bet Leḥem ve- } \\
\text { bulabdi cumle kišileri o } \\
\text { šehernin olar ičun ve- } \\
\text { dediler bumu Nāomī }\end{array}$ & $\begin{array}{l}\text { da yürüdüler ekileri } \\
\text { kelgenlerinče degin beyt } \\
\text { lexem-ge da oldu qačan } \\
\text { ki keldiler beyt lexem-ge } \\
\text { da engeme-lendiler ğümle } \\
\text { oturyanlarï ol šeher-niך } \\
\text { üsterine da eyttiler, eger } \\
\text { bumïdïr noomi? }\end{array}$ & $\begin{array}{l}\text { da-vardilar ekisi } \\
\text { kelganlarina degin } \\
\text { Bet Lehem ga da-edi } \\
\text { kelganlari kibik Bet Lehem } \\
\text { ga da-mugradi karča ol } \\
\text { šahar ustlarina da-ayțịilar } \\
\text { bumudir Nāomī }\end{array}$ \\
\hline $\begin{array}{l}\text { ve-dedi olara čaxirmaniz } \\
\text { bana Nā’omī čaxiriniz } \\
\text { bana Mārā zire ači ețti beni } \\
\text { Qadir Ṭayri peq ğāyyeṭ }\end{array}$ & $\begin{array}{l}\text { da eytti olarya olmay aysïz } \\
\text { čaqïryan-lar maya noomi } \\
\text { čaqïrïnïz mana aği ğanlï ki } \\
\text { ağitti qadir tayrï meni ziyade }\end{array}$ & $\begin{array}{l}\text { da-ayțți alarga ațamaniz } \\
\text { maya Nāeomī ațayiz maya } \\
\text { ači ki ači ețți Qadir Țeyri } \\
\text { maya asri }\end{array}$ \\
\hline $\begin{array}{l}\text { ben dolo gitțim ve-boš } \\
\text { dondurdu beni Ya neičun } \\
\text { čaxirsiz bana Nāomī ve-Ya } \\
\text { qinadi beni ve-Qadir Ṭayri } \\
\text { fenā ețti bana }\end{array}$ & $\begin{array}{l}\text { men dollu kittim, ... da boš } \\
\text { qaytardï meni adonay ... } \\
\text { ne üčün bu siz čaqïraysïz } \\
\text { maya noomi da alïndan } \\
\text { adonay-nïy šaatlïq etti } \\
\text { minim ... da qadir teyri } \\
\text { yaman etti maya }\end{array}$ & $\begin{array}{l}\text { man țolu vardim da-boš } \\
\text { qayțardi meni YWY nučun } \\
\text { ațarsiz maya Nāomī ve- } \\
\text { YWY qayndi meni da-Qadir } \\
\text { Ṭeyri yaman ețți maya }\end{array}$ \\
\hline $\begin{array}{l}\text { ve-dondu Nāomī ve-Rut } \\
\text { haMo<abiyah gelini onun } \\
\text { ilen ol donen țarlasindan } \\
\text { Mo<ab nin ve-olar geldiler } \\
\text { Bet Lehem ge ilkinde oraği } \\
\text { arpalarin }\end{array}$ & $\begin{array}{l}\text { da qayttï noomi da rut } \\
\text { hamoavia kelini barabarïna } \\
\text { ki qayttï tüzlerinden moav- } \\
\text { nin da keldiler beyt lexem- } \\
\text { ge ... ki oldu arpa-lar-dan }{ }^{38}\end{array}$ & $\begin{array}{l}\text { da-qayțti Nāomī da-Rut ol } \\
\text { Mo<abli kelini birgasina } \\
\text { ki qayțti țuzlarindan } \\
\text { Mo<abniy da-alar keldilar } \\
\text { Bet Lehem ga ilkanda } \\
\text { oraginin arpalarnin }\end{array}$ \\
\hline
\end{tabular}




\section{Appendix III}

In this Appendix, my purpose is to illustrate that the language chosen by the $19^{\text {th }}$ century (?) Rabbanite Qrimčaqs was very much modelled on that of the Crimean tradition of Bible translations. The text is Daniel 1:1-4 and is taken from a published image of a $20^{\text {th }}$ century copy, Krymčaki, ed. by D.I. Rebi \& V.M. Lombrozo, Simferopol' 2001, p. 35. The English translation is taken from the King James version.

ucungi yyilda ḥanliqina Yehoyaqim nin ḥani Yehudah nin keldi Nebuknadnecar ḥani Babel nin Yerušalayim ga da ḥeseret qurdu usțune

In the third year of the reign of Jehoiakim king of Judah, Nebuchadnezzar king of Babylon came to Jerusalem and besieged it.

da dedi H' qoluna ošol Yehoyaqim nin ḥani Yehudah nin da birazindan sağițlari avi ol țayrinin da gețirdi olarni yyerine Babel nin evine 'abodah zarah sinin da ošol sağițlarini kețirdi evine ḥaznasi abodah zarah sinin

And the Lord delivered Jehoiakim king of Judah into his hand, along with some of the articles from the temple of God. These he carried off to the temple of his god in Babylonia[a] and put in the treasure house of his god.

da ețți ol han Ašpanaz ga ağasi qadim ağalarnin gețirmeğa oğullarindan Yisraelnin da zura'atindan ol ḥanliq nị da ol beğlerden

Then the king ordered Ashpenaz, chief of his court officials, to bring into the king's service some of the Israelites from the royal family and the nobility

ballar ki yoḥtur ollarda cumle saqațlị̣ da yahšilari korumnin da aylayanlar cumle usulluh da da bilgenleri bilmeknin da aylananlari anlamahnniy da ki quwaț var dir olarda țurmağa sarayda ol ḥan nin da oğerețme olarga seper da țili Kasdim nin

Young men without any physical defect, handsome, showing aptitude for every kind of learning, well informed, quick to understand, and qualified to

${ }^{38}$ The text towards the end is overly paraphrased. 
serve in the king's palace. He was to teach them the language and literature of the Babylonians. The king assigned them a daily amount of food and wine from the king's table. They were to be trained for three years, and after that they were to enter the king's service.

\section{BIBLIOGRAPHY}

ADLER, Elkan Nathan. 1905. About Hebrew Manuscripts. Oxford University Press.

BASKaKov, N. A., A. Zajončkovskij, S. M. Šapšal (eds.). 1974. Karaimsko-russkopol'skij slovar'. Moskva: Russkij Jazyk.

Chernin, Ze'ev (Velvl). 2000/2001. The Hebrew Pronunciation of the Krymchaks. Hebrew Linguistics 48, 31-38.

זאב (וועלוול) טשרנין, המבטא העברי של היהודים הקרימצ'אקים, בלשנות עברית 48 (טבת תשס"א),

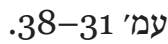

Harviainen, Tapani. 1998. The Karaite Community in Istanbul and Their Hebrew. Jewish Studies in a New Europe. Proceedings of the Fifth Congress of Jewish Studies in Copenhagen 1994 Under the Auspices of the European Association for Jewish Studies, ed. by Haxen, Ulf \& Trautner-Kromann, Hanne \& Salamon Goldschmidt, Karen Lisa. Copenhagen: C. A. Reitzel, 349-356

IANBAY, Iala \& Marcel Erdal, 1998. The Krimchak Translation of a Targum Šeni of the Book of Ruth. Meditteranean Language Review, 10, 1-53.

Jankowski, Henryk. 2012. Rouned-unrounded Vowel Harmony in Turkish. The Szeged Conference, Proceedings of the $16^{\text {th }}$ International Conference on Turkish Linguistics Held on August 20-22, 2010 in Szeged, ed. by Eva KincsesNagy and Mónika Biacsi, technical editor Béla Kempf, Szeged, 257-264.

ManN, Jacob. 1935. Texts and Studies in Jewish History and Literature. Cincinnati: Hebrew Union College Press.

SHAPIRA, Dan. 2003a. Avraham Firkowicz in Istanbul (1830-1832): Paving the Way for Turkic Nationalism, Ankara: KaraM Publishing Co.

ShapIRA, Dan. 2003b. Avraham Firkowicz in Istanbul. Jewish Texts and Studies 1, 1-19 [Hebrew].

דן שפירא, אברהם פירקוביץ בקושטא, חדשים גם ישנים א (תשסג) עמ' 1-22 (חלק עברי)

SHAPIRA, Dan. 2013. The Karaim Translation of the Book of Nehemia Copied in the $17^{\text {th }}$ century's Crimea and Printed in 1840/1 at Gözleve, on the Copyist of the Manuscript, and some Related Issues. Karaite Archives 1, 133-198. 
Dan Shapira obtained his Ph.D. in 2000 on Studies in Zoroastrian Exegesis: Zand (in English, two volumes) under the supervision of Prof. Shaul Shaked, HUJI; and since 2013 has held the post of full professor at the Department of Middle Eastern Studies, and is the Feldman Professor of the History and Culture of Eastern European Jewry, Faculty of Jewish Studies, Bar-Ilan University, Israel. 
The Elyashevitch-Babadjan MS is, practically, identical with the text published by Yișhaq Tırıšqan in 1841 (the Gözleve Bible):

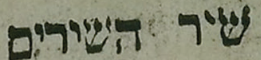

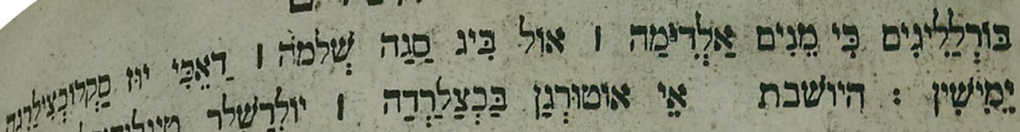

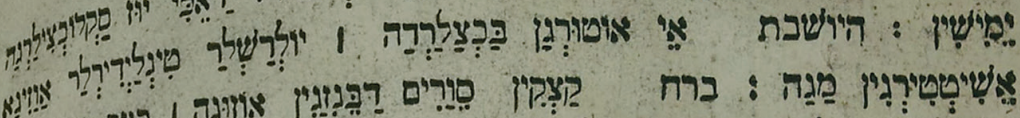

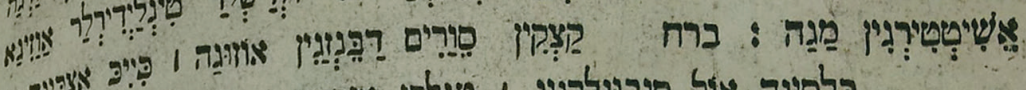
א.

\section{กา กรัด}

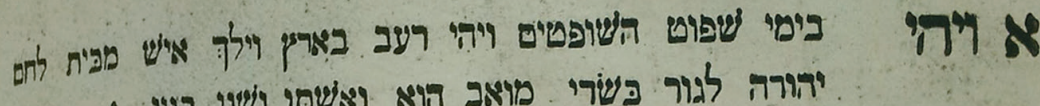

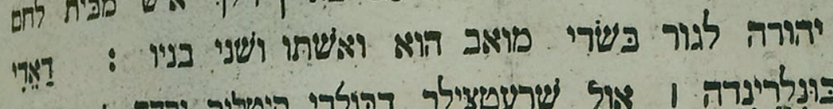

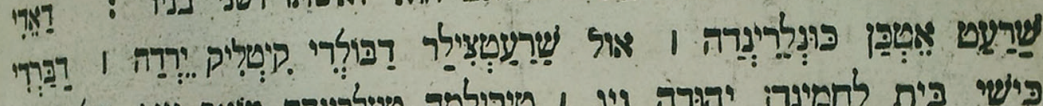

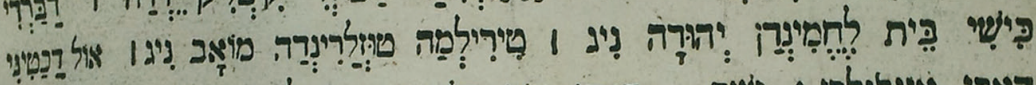

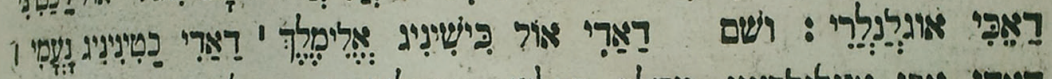

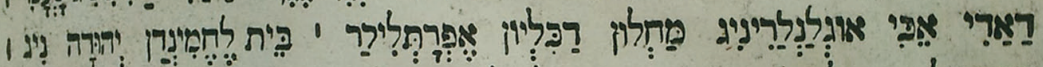

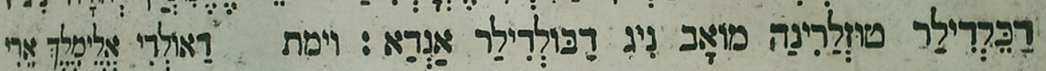

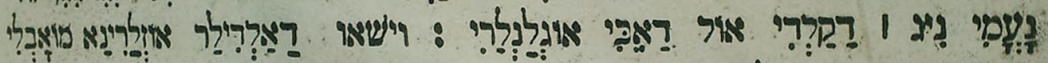

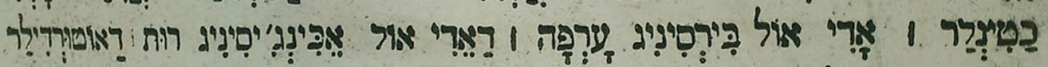

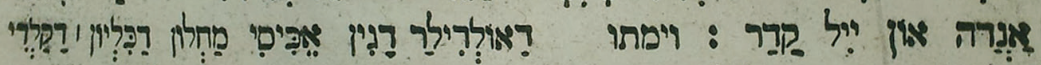

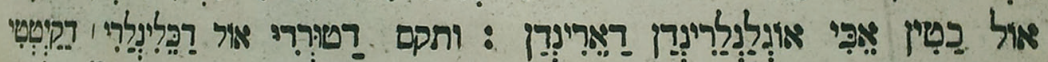

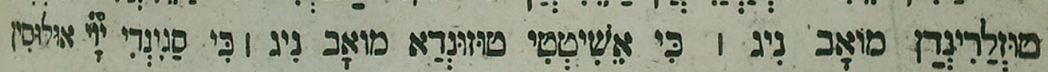

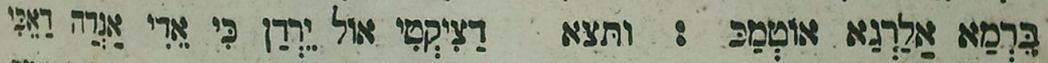

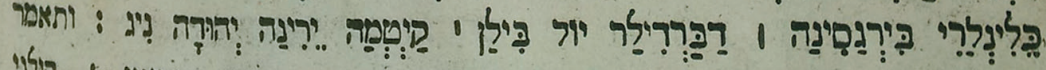

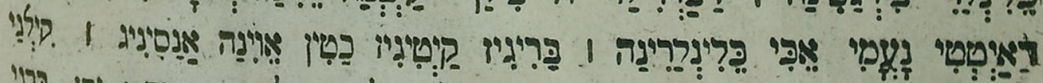

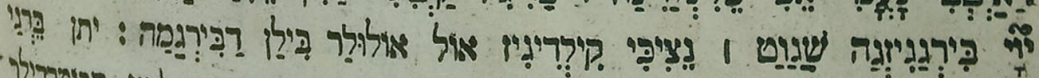

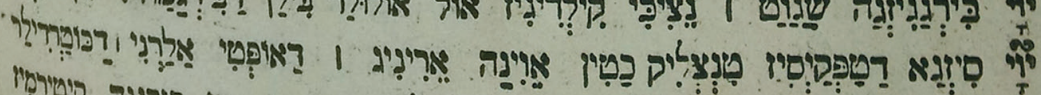

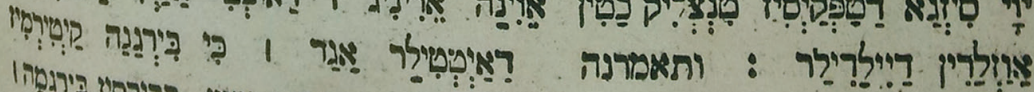

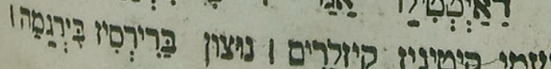
מיר

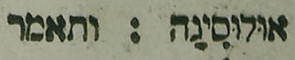




\section{ก}

\section{กา}

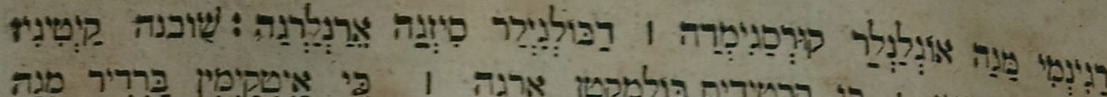

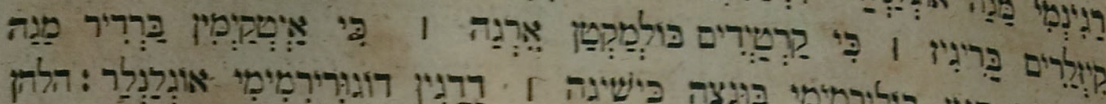

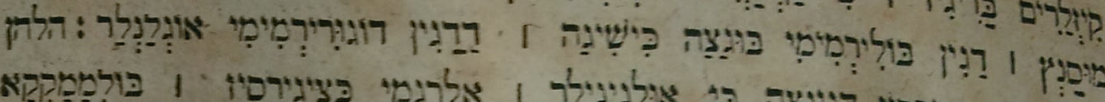

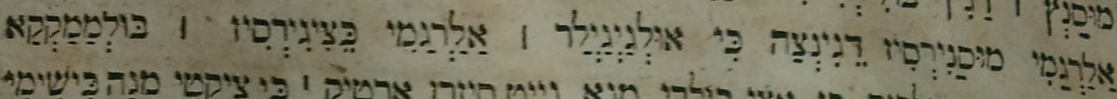

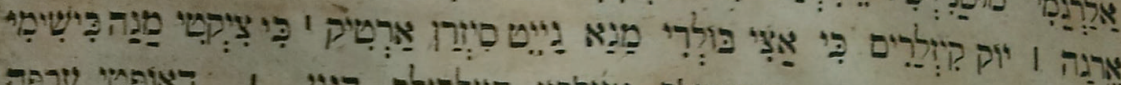
กาำ

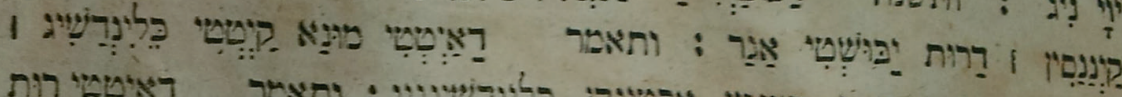

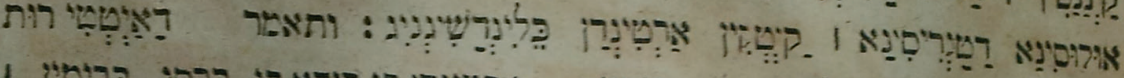

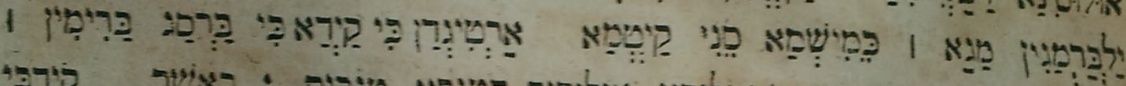

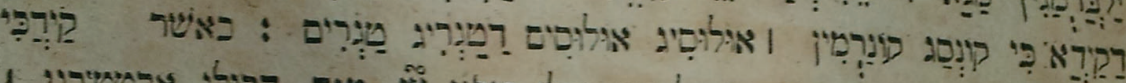

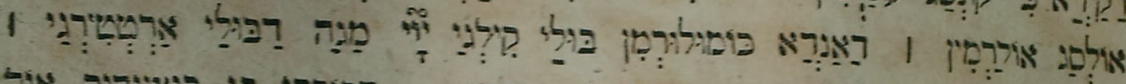

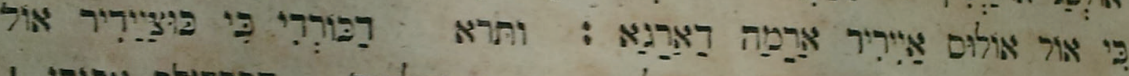

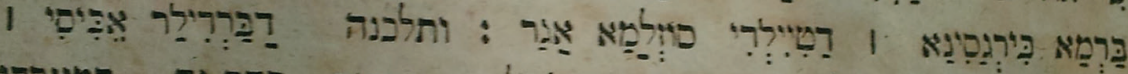

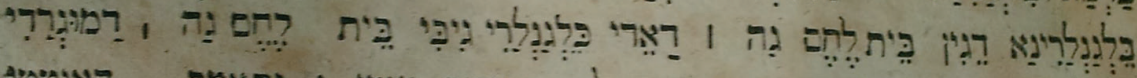

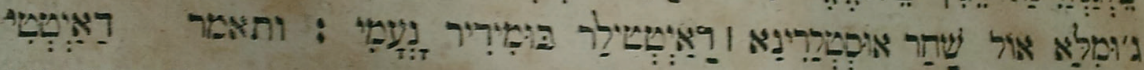

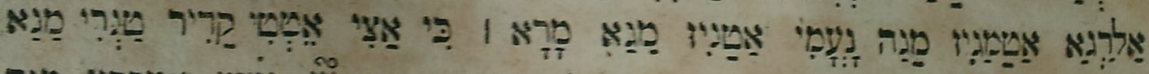

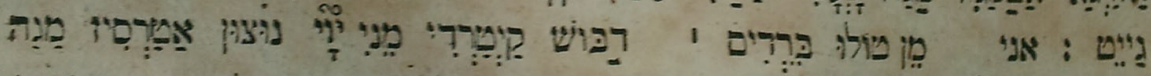

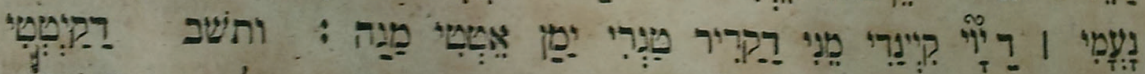

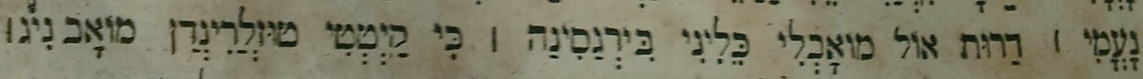

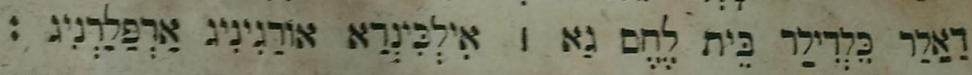

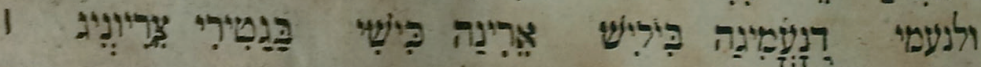

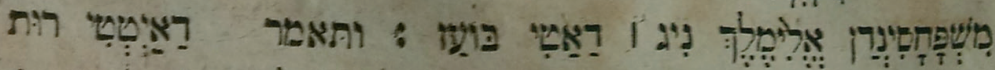

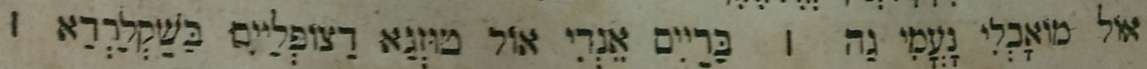

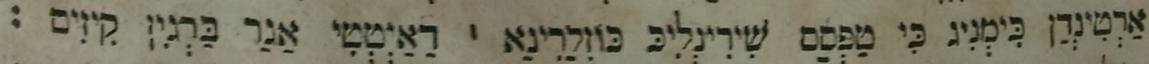

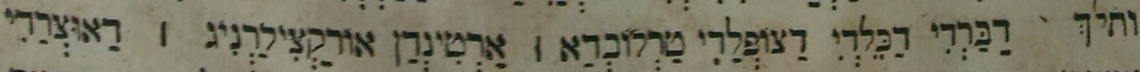

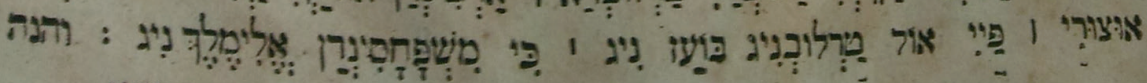
Kมเด 


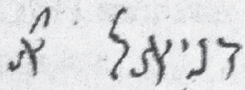

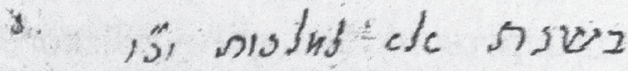

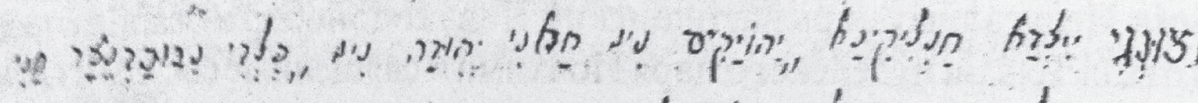

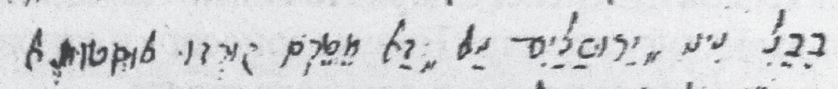

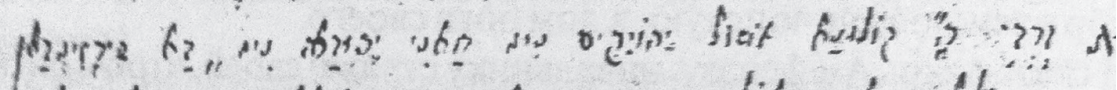

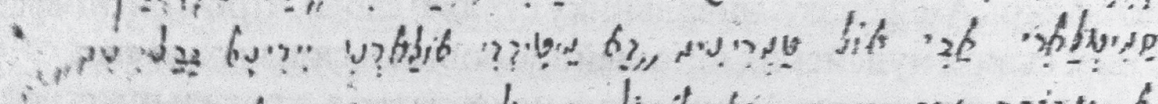

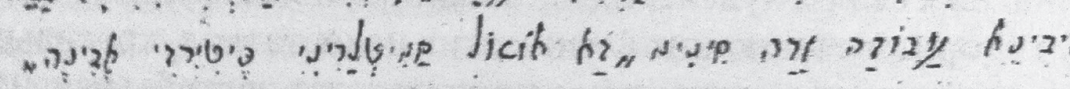

$\therefore \quad \therefore \quad$ a $\quad$ a

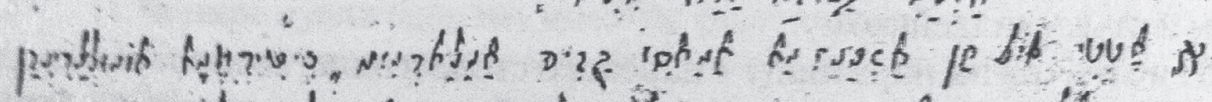

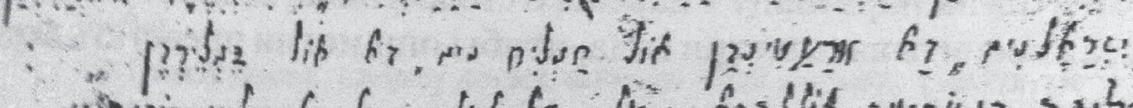

तhingris 1)

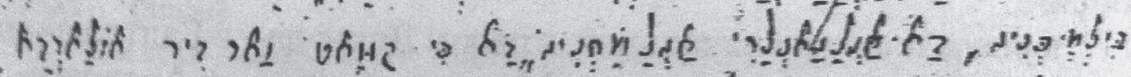

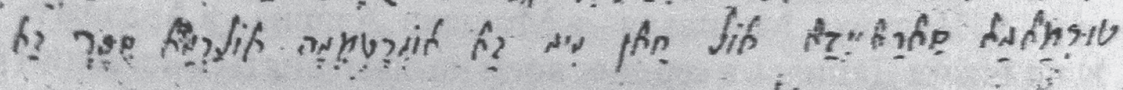
20 tom

Старинная крымчакская рукопись - джконка И.Ю. Габая, перевод на крымчакский язык «Книги пророка Даниила» из Ветхого Завета (фрагмент). 